\title{
Separating the Components of Default Risk: A Derivative-Based Approach
}

\author{
Job Market Paper
}

\author{
Anh Le ${ }^{1}$ \\ This draft: January 16, 2007
}

\begin{abstract}
${ }^{1} \mathrm{PhD}$ Candidate at the Stern School of Business, 44 West Fourth St, Suite 9-195, New York University, New York, NY 10012, phone: 1-212-998-0321, email: ale0@stern.nyu.edu. The most recent version of the paper can be downloaded from http://pages.stern.nyu.edu/ ale0/. I owe my gratitude to my advisers, Ken Singleton and Raghu Sundaram, for their invaluable guidance. I would like to thank my other committee members - Yakov Amihud, Jennifer Carpenter, Sanjiv Das, Robert Whitelaw - and Viral Acharya, Linda Allen, Menachem Brenner, Steve Figlewski, Kose John, Haitao Li, Matthew Richardson, Anthony Saunders for their feedback and encouragement. This paper greatly benefits from discussions with seminar participants at the NYU Finance Department workshop, the Moody's workshop series and the 2006 Trans-Atlantic Conference. I would like to thank Edward Altman at NYU, Richard Cantor and Roger Stein at Moody's for sharing Moody's Default Risk Service data. Computational assistance by Vinh Le is greatly appreciated. All errors are mine.
\end{abstract}




\begin{abstract}
In this paper, I propose a general pricing framework that allows the risk-neutral dynamics of loss given default $\left(L^{\mathbb{Q}}\right)$ and default probabilities $\left(\lambda^{\mathbb{Q}}\right)$ to be separately and sequentially discovered. The key is to exploit the differentials in $L^{\mathbb{Q}}$ exhibited by different securities on the same underlying firm. By using equity and option data, I show that one can efficiently extract pure measures of $\lambda^{\mathbb{Q}}$ that are not contaminated by recovery information. Equipped with this knowledge of pure default dynamics, prices of any defaultable security on the same firm with non-zero recovery can be inverted to compute the associated $L^{\mathbb{Q}}$ corresponding to that particular security. Using data on credit default swap premiums, I show that, crosssectionally, $\lambda^{\mathbb{Q}}$ and $L^{\mathbb{Q}}$ are positively correlated. In particular, this positive correlation is strongly driven by firms' characteristics, including leverage, volatility, profitability and qratio. For example, $1 \%$ increase in leverage leads to .14\% increase in $\lambda^{\mathbb{Q}}$ and $.60 \%$ increase in $L^{\mathbb{Q}}$. These findings raise serious doubts about the current practice, by both researchers and practitioners, of setting $L^{\mathbb{Q}}$ to a constant across firms.
\end{abstract}




\section{Introduction}

Central to pricing corporate liabilities are the two main components of default risk: the risk neutral probability of default $\left(\lambda^{\mathbb{Q}}\right)$ and the risk neutral expected loss given default $\left(L^{\mathbb{Q}}\right) .{ }^{1}$ While a great number of studies have focused on modeling default probabilities ${ }^{2}$, research on loss given default ${ }^{3}$ has received far less attention. This uneven treatment is, in part, due to the difficulty in simultaneously disentangling $L^{\mathbb{Q}}$ and $\lambda^{\mathbb{Q}}$ from market data. For example, Pan and Singleton (2006) show that, while possible in principle, separation of $L^{\mathbb{Q}}$ and $\lambda^{\mathbb{Q}}$ using information from (only) linear securities such as bonds or credit default swap $(C D S)$ contracts may prove difficult in practice. ${ }^{4}$ In order to learn about $\lambda^{\mathbb{Q}}$, it is often necessary to invoke an assumption on the part of the loss rate $L^{\mathbb{Q}}$ (and vice versa). Until recently, the standard treatment, by both academics and practitioners, has been to set $L^{\mathbb{Q}}$ at some constant.

In this paper, I propose a pricing framework that allows the risk-neutral dynamics of $L^{\mathbb{Q}}$ and $\lambda^{\mathbb{Q}}$ to be separately and sequentially recovered. This framework is built from the insights offered by Madan and Unal (1998), Duffie and Singleton (1999) and Das and Sundaram (2003) that separate identification of $L^{\mathbb{Q}}$ and $\lambda^{\mathbb{Q}}$ can be achieved from prices of multiple securities with different payout structures but subject to the same default arrival risk. ${ }^{5}$ Specifically, given that equity prices and especially call option prices fall close to zero in the event of default, equity and option markets contain "pure" information about $\lambda^{\mathbb{Q}}$, with minimal inferences from recovery information. Subjecting this $\lambda^{\mathbb{Q}}$ to prices of more senior securities of the same underlying firm with non-zero recovery, an estimate of $L^{\mathbb{Q}}$ corresponding to these securities can be recovered. An obvious class of defaultable security applicable in this analysis is corporate bonds. Another more recent contract particularly suitable to this analysis is the credit default swap $(C D S)$ contract - essentially an insurance contract against default by a firm on its bonds. With the tremendous growth in $C D S$ markets $^{6}, C D S$

\footnotetext{
${ }^{1} L^{\mathbb{Q}}$ is related to the risk neutral expected recovery given default $R^{\mathbb{Q}}$ by the simple equation: $L^{\mathbb{Q}}=1-R^{\mathbb{Q}}$.

${ }^{2}$ Pioneered by Altman (1968) and Merton (1974), default risk models include Black and Cox (1976), Geske (1977), Vasicek (1984), Litterman and Iben (1991), Kim, Ramaswamy, and Sundaresan (1993), Hull and White (1995), Longstaff and Schwartz (1995), Jarrow and Turnbull (1995), Jarrow, Lando, and Turnbull (1997), Madan and Unal (1998), Lando (1998), Duffie and Singleton (1999) among many others.

${ }^{3}$ Altman and Kishore (1996) and Acharya, Bharath, and Srinivasan (2004), for example, provide analysis on actual recoveries of defaulted securities. Das (2005) provides a survey of the literature on recovery risk.

${ }^{4}$ It should be noted that Pan and Singleton (2006), in pricing $C D S$ contracts, adopt the recovery of face value assumption which, therefore, permits separate identification of $L^{\mathbb{Q}}$ and $\lambda^{\mathbb{Q}}$. Under an alternative recovery assumption - the recovery of market value -, Duffie and Singleton (1999) show that it is impossible to separate $L^{\mathbb{Q}}$ and $\lambda^{\mathbb{Q}}$ unless nonlinear securities such as bonds with embedded optionality or options on bonds are available.

${ }^{5}$ While Das and Sundaram (2003) and Duffie and Singleton (1999) only present examples illustrating how $L^{\mathbb{Q}}$ and $\lambda^{\mathbb{Q}}$ can be identified, Madan and Unal (1998) carry out an empirical investigation of $L^{\mathbb{Q}}$ and $\lambda^{\mathbb{Q}}$ using debts of different seniorities.

${ }^{6}$ According to statistics provided by The International Swaps and Derivatives Association, available from www.isda.org, the notional amount of credit default swaps grew by $52 \%$ in the first six months of 2006 to $\$ 26$ trillion. The annual growth rate is $109 \%$ from $\$ 12.4$ trillion at mid-year 2005 . The growth rates are, respectively, $123 \%$ and $128 \%$ in 2003 and 2004 .
} 
contracts present a promising channel to study default and recovery dynamics and will be employed in this paper.

On the other hand, prior studies such as Madan and Unal (1998), Unal, Madan, and Guntay (2001) and Bakshi, Madan, and Zhang (2006) typically use multiple debt securities in achieving identification of $\lambda^{\mathbb{Q}}$ and $L^{\mathbb{Q}}$. For instance, Madan and Unal (1998) combine prices of two securities with different $L^{\mathbb{Q}}$ 's in a way that cancels out the $\lambda^{\mathbb{Q}}$ component from these prices. Coupled with an assumed structure of how the two $L^{\mathbb{Q}}$ 's relate, the authors are able to arrive at an estimate of $L^{\mathbb{Q}}$ for each of these securities. These $L^{\mathbb{Q}}$ 's are in turn combined with the two securities prices to form an estimate of $\lambda^{\mathbb{Q}}$. Bakshi, Madan, and Zhang (2006) adopt a specific parametric debt model in a reduced form setting in which the recovery rate is a function of the default arrival rate which in turn depends only on the short rate. After estimating the relevant parameters by matching model-implied and market prices of debts with varying maturities, the authors are able to arrive at estimates of default probabilities and recovery rates. The common key to identification of $\lambda^{\mathbb{Q}}$ and $L^{\mathbb{Q}}$ in these studies is to exploit the cross-sectional variations in prices of bonds issued by the same underlying firm ${ }^{7}$.

Compared to the prior literature, the most innovative feature of the current approach lies in its usage of equity data and call option data in arriving at clean measures of $\lambda^{Q}$. Equity prices, corresponding to the last claimant of the firm's assets, should be at least as informative about the default dynamics as debt prices. The most direct evidence of this is the popularity of Merton-type models (adopted by Moody's KMV and JPMorgan's E2C model and many academic papers such as Huang and Huang (2003)) which typically translate variations in stock prices into variations in default probabilities. In addition, option data have also been shown to contain information relevant to the creditworthiness of the underlying firms. For example, Cremers, Driessen, Maenhout, and Weinbaum (2004) show that option implied volatilities are able to explain very well the cross-sectional variations of the credit default swap (CDS) premiums. Moreover, equity prices and particularly call option prices are typically $L^{\mathbb{Q}}$-insensitive, thereby naturally presenting a clean channel to study the dynamics of $\lambda^{\mathbb{Q}}$ with minimal inference from $L^{\mathbb{Q}}$-information.

Why should equity prices and call option prices be $L^{\mathbb{Q}}$-insensitive? In other words, why should equity prices and call option prices are minimally affected by recovery information? For equity holders, zero-recovery is dependent on adherence to strict priority rules. To this extent, some evidence provided by Bharath (2006) suggests that during the period from 1998 to 2003, the extent of absolute priority violation is minimal. Using a comprehensive database on corporate bankruptcies, the author shows that, in more than 80 percent of the cases, shareholders lose the full value of their investments; in most of the remaining cases, shareholders can only claim less than 1 percent of the asset value of the firms ${ }^{8}$. This evidence suggests that not only are strict priority rules being complied with but also firms tend to

\footnotetext{
${ }^{7}$ This is understandable since pure time series variation is only informative about physical quantities whereas the variables of interest $\lambda^{\mathbb{Q}}$ and $L^{\mathbb{Q}}$ are risk-neutral by nature.

${ }^{8}$ This has not taken into account the effect of distress or liquidity costs due to various consequences of defaults, one of which is equity being de-listed from main trading venues.
} 
default well inside the insolvency region. ${ }^{9}$ As for call options, since there is essentially no default risk on the part of the option writer ${ }^{10}$, the only default risk relevant to call option holders comes from the underlying firm. Consequently, call option prices do not depend on recovery information directly. Rather, the only channel through which recovery information can affect call option prices is the implied distribution of stock price as the firm approaches financial distress. To this extent, even if equity experiences non-zero recovery, equity recovery information only affects the lower tail of the distribution of stock price and thus would not be material for call option prices for a wide range of strike prices.

Having a pure measure of $\lambda^{\mathbb{Q}}$ is convenient, since it can be applied to any security with non-zero recovery to back out the corresponding $L^{\mathbb{Q}}$. For instance, whereas Madan and Unal (1998) require the existence of two debt securities with different seniorities, with clean measures of $\lambda^{\mathbb{Q}}$ implied from equity and option data, recovery information of each of these debt securities can be implied independently and even for firms who issue only one class of debt. Likewise, Bakshi, Madan, and Zhang (2006) require sufficiently large cross-section of bonds $^{11}$ in their estimation. With a clean measure of $\lambda^{\mathbb{Q}}$, such a requirement is no longer necessary.

The current approach also offers a certain degree of modeling richness absent from the prior studies in allowing for both: diffusion type of defaults - a typical feature of structural models of default - and jump-to-defaults - typical of reduced-form models. On the other hand, Madan and Unal (1998), Unal, Madan, and Guntay (2001) and Bakshi, Madan, and Zhang (2006) all set up their model in a reduce-form framework. Specifically, within the current framework, firms can jump to default with an intensity dependent on the level of stock price and/or the level of short rate. In addition, even when the jump intensity is set to zero, firms can still "diffuse" to default since the equity follows a stochastic process that allows absorption at zero. While the "diffusion" channel of default resembles that of Merton-type models, the current approach does not require specification of a default trigger boundary for firms' asset value since it works directly with equity. Although this procedure may omit some information content from the balance sheet, it can as well help avoid any possible bias from using accounting data ${ }^{12}$.

\footnotetext{
${ }^{9}$ However, it should be noted that the literature on corporate bankruptcies (e.g. Gilson, John, and Lang (1991), Frank and Torous (1989)) has shown that absolute priority is often violated, with shareholders gaining some fraction of the defaulted firms' values. To this extent, any degree of violation of absolute priority can, in principal, be accommodated within the current framework. To the extent that absolute priority is assumed to be observed, empirical results of this paper should be interpreted in the context of this assumption. Depending on the magnitude, the consequence of ignoring absolute priority violation is an underestimation of default probabilities.

${ }^{10}$ As the issuer of all options, the Options Clearing Corporation (OCC) essentially takes the opposite side of every option traded. The OCC substantially reduces the credit risk aspect of trading securities options as the OCC requires that every buyer and every seller have a clearing member and that both sides of the transaction are matched. It also has the authority to make margin calls on firms during the trading day. In addition, the OCC has a AAA credit rating from Standard \& Poor's Corporation.

${ }^{11}$ For this reason, they cannot carry out their analysis with monthly data since the available monthly cross-section is not sufficiently large.

${ }^{12}$ Merton-type models usually use book values of short-term debt plus one half of book values of long-term debt as default trigger point, although no formal theoretical or empirical justification exists. Other default
} 
The current approach also departs from the the current literature to the extent that it allows for general specifications of the dynamics of $L^{\mathbb{Q}}$. In choosing a fixed $L^{\mathbb{Q}}$, researchers tend to use historical averages of actual losses reported in prior studies ${ }^{13}$; it is not uncommon to see a fixed loss rate of 50 percent $^{14}$. However, at least two issues arise when using historical values. First, they are ex post in nature and do not reflect newly available information as it arrives in the markets. Second, historical averages of losses given default relate to the objective probability measure. Therefore, by equating $L^{\mathbb{P}}=L^{\mathbb{Q}}$ in pricing, one effectively assumes that investors place no premium on recovery risk. This assumption is rather unrealistic given the pronounced findings by Altman, Brady, Resti, and Sironi (2005) that actual recoveries show significant cross-sectional variations. In particular, Altman, Brady, Resti, and Sironi (2005) find physical probabilities of default $\lambda^{\mathbb{P}}$ are negatively related to the physical recovery rates $R^{\mathbb{P}}$ at the aggregate level.

Though Altman, Brady, Resti, and Sironi (2005)'s findings strongly suggest that it is not correct to set $L^{\mathbb{P}}=L^{\mathbb{Q}}$ in pricing, their findings do not suggest that the current practice of setting $L^{\mathbb{Q}}$ to a constant is incorrect. In fact, if we can define a measure of recovery risk premium $\pi$, linking $L^{\mathbb{P}}$ and $L^{\mathbb{Q}}$ in a simple way: $\pi=L^{\mathbb{P}}-L^{\mathbb{Q}}$, it is possible that the riskneutral loss given default $L^{\mathbb{Q}}$ can still be a constant while all the variations of the physical loss given default $L^{\mathbb{P}}$ are attributable to changes in recovery risk-premiums $\pi$. Likewise, it is also possible that the physical relationship between $L^{\mathbb{P}}$ and $R^{\mathbb{P}}$ is entirely attributable to the interactions between default risk-premiums and recovery risk premiums although no similar relationship between their risk-neutral counter-parts, $L^{\mathbb{Q}}$ and $R^{\mathbb{Q}}$, exists. In short, the dynamics under the risk-neutral measures and the physical measures could be so different that knowledge about $L^{\mathbb{P}}$ and $\lambda^{\mathbb{P}}$ does not allow us to make meaningful inferences about $L^{\mathbb{Q}}$ and $\lambda^{\mathbb{Q}}$.

In this regard, the $L^{\mathbb{Q}}$ measures implied by the current approach display strong crosssectional variations. In particular, I find evidence that $L^{\mathbb{Q}}$ and $\lambda^{\mathbb{Q}}$ are positively related. This result is consistent with findings by Das and Hanouna (2006) who compute $L^{\mathbb{Q}}$ and $\lambda^{\mathbb{Q}}$ using a different method which pre-specifies the relation between $L^{\mathbb{Q}}$ and $\lambda^{\mathbb{Q}}$. Further investigations reveal that the correlation between these two variables is strongly influenced by firms' characteristics, including leverage, volatility, profitability and q-ratios. The effect of leverage on $L^{\mathbb{Q}}$ and $\lambda^{\mathbb{Q}}$ is, for example, both statistically and economically significant. Holding other characteristics of the firms constant, $1 \%$ increase in a firm's leverage, measured by debt divided by total book value of asset, leads to $.14 \%$ increase in $\lambda^{\mathbb{Q}}$ and $.60 \%$ increase in $L^{\mathbb{Q}}$. Given the wide variations in leverage in the cross-section of firms, these findings raise serious doubts about the current practice, by both researchers and practitioners, of setting $L^{\mathbb{Q}}$ to a constant.

However, the cross-sectional averages of $L^{\mathbb{Q}}$ seem to be stable over the sample period from

threshold exists as well. For example, book value of total liabilities is used in Eom, Helwege, and Huang (2004).

${ }^{13}$ For example, Altman and Kishore (1996) or Acharya, Bharath, and Srinivasan (2004).

${ }^{14}$ For example, Carr and Wu (2005) and JP Morgan's E2C model employ an expected loss rate of $50 \%$. Huang and Huang (2003) use an expected loss rate of $51.31 \%$ across all ratings. Conversations with $C D S$ traders indicate that they adopt a flat rate of $60 \%$ for senior unsecured bonds across all ratings. 
2002 to 2005 . The stability of $L_{t}^{\mathbb{Q}}$ over the sample period, in the context of the improving credit environment observed between 2002 and $2005^{15}$, is consistent with a decreasing overall recovery risk premium ${ }^{16}$.

The literature on estimating recoveries is growing ${ }^{17}$. Studies using debt data to infer recovery information include Madan and Unal (1998), Frye (2000), Unal, Madan, and Guntay (2001) and Bakshi, Madan, and Zhang (2006). Jarrow (2001) proposes a framework for simultaneously estimating recovery rates and default probabilities by modeling the dividend and the bubble component in equity prices. Guo, Jarrow, and Zeng (2005) model recovery rates in a reduced form setting. The current paper adds to this literature by setting up a general framework that allows recovery information to be extracted from derivative prices. Apart from the flexibility in modeling recovery dynamics as discussed above, this paper also combines the flavors of both the structural and the reduced-form approach to modeling default risk. Within the current framework, a firm can either jump or diffuse to default. Since pure diffusion models are typically unable to explain short-term credit dynamics (see, for example, Zhou (2001)), allowing for the possibility of jump-to-defaults seems important.

The proposed framework is similar in spirit to Das and Sundaram (2006)'s work in which pricing is performed on a lattice space of equity prices and short-rates in the presence of defaults. Das and Sundaram (2003) also suggest that recovery information can be implied by combining equity and option data but they do not implement their model. Das and Hanouna (2006) also use $C D S$ data to imply recovery information by bootstrapping over the term structure of $C D S$ premiums using a variety of parametric relations between default probabilities and recoveries. Finally, Pan and Singleton (2006) analyze default and recovery information implicit from the term structure of the sovereign $C D S$ markets. Although the default process under the current approach is a function of observables, Pan and Singleton (2006) model default as a completely latent process in a reduced-form setting.

This paper is organized as follows. The second section provides a description of a typical $C D S$ contract. Next, the general treatment on pricing derivatives in the presence of defaults, using a lattice approach, is laid out. In this section, I will show (1) how to calibrate option data into this framework to learn about the risk-neutral dynamics of defaults and (2) how to combine these dynamics and data on $C D S$ premiums to back out recovery dynamics. The fourth section provides a description of the data. Employing a specialized version of the framework in which analytical pricing is feasible, the subsequent two sections report findings on the implied dynamics of default probabilities and losses given default respectively. The last section concludes.

\footnotetext{
${ }^{15}$ In 2002 , the US saw the worst corporate credit conditions in a decade with a record default rate of $16.4 \%$ with $\$ 109.8$ billion in defaults during the year and a very large number of downgrades. High yield default rates in 2003, 2004 and 2005 are $5.0 \%, 1.5 \%$ and $3.1 \%$ respectively. The notional amounts in defaults are also substantially lower.

${ }^{16}$ Because, the difference between $L_{t}^{\mathbb{P}}$ and $L^{\mathbb{Q}}$ indicates the magnitude of recovery risk premium.

${ }^{17}$ For a recent survey of the literature, see Das (2005).
} 


\section{A typical $C D S$ contract}

A $C D S$ contract is analogous to an insurance contract ${ }^{18}$ that provides protection against credit losses associated with a default on pre-specified referenced securities. The purchaser of a $C D S$ contract effectively exchanges the credit risk of the issuer of the referenced securities for the credit risk of the seller of the $C D S$ contract - who is typically a highly-rated financial intermediary $^{19}$. The purchaser agrees to pay to the seller a periodic fee until the maturity date of the contract or until a default event, as defined in the credit confirmation, has occurred. In return, the seller is bound to pay the credit purchaser a pre-specified marketbased amount or a pre-fixed fraction of the value of the referenced security contingent upon the occurrence of a credit default. Typically, the amount payable by the seller is the difference between the actual market value of the defaulted security and the referenced security's initial principal.

The International Swaps and Derivatives Association provides a master credit confirmation that is commonly used in most $C D S$ contracts. According to this master agreement, a credit default is defined to include a wide range of events, from bankruptcy, obligation acceleration, missed interest or principal payments, repudiation of payments to distressed exchanges or restructuring of securities. Although most other credit events can be easily agreed upon by parties to a $C D S$ contract, one exception is the restructuring criterion which typically involves renegotiation between the issuer and the majority of the holders of the referenced securities in a way that worsens the financial position of the securities hold$\mathrm{ers}^{20}$. Due to this potential confusion, some market participants ${ }^{21}$ have decided to trade $C D S$ contracts without any restructuring clause at all. One additional complication inherent with restructuring is the cheapest-to-deliver option, in which the protection buyer has the option to deliver the securities with the lowest value, typically bonds with longer maturities. To this extent, the master agreement allows for a "Modified Restructuring" type that specifies a maturity limitation of deliverable obligations to 30 months after the scheduled termination date. Introduced in May 2001, "Modified Restructuring" has been widely adopted by North American markets, and is the choice in more than 95 percent of single-name $C D S$ contracts in Fitch Rating's Valuspread database ${ }^{22}$.

When a default event occurs, typically two settlement choices are available: (1) a physical

\footnotetext{
${ }^{18} \mathrm{~A} C D S$ contract has also been described as similar to a standby letter of credit

${ }^{19}$ Counter-party risk - the risk that the seller of a $C D S$ contract also defaults in the event of a default by the issuer of the referenced security - is often assumed negligible. Though it may vary from seller to seller, buyers of $C D S$ contracts can require the sellers to deposit an agreed amount into an escrow account. This amount can be used to make settlements, if needed, in the case the seller himself defaults within the maturity of the $C D S$ contract.

${ }^{20}$ Xerox's June 2002 refinancing, for example, was not intended to fall within the "Restructuring" definition, yet a number of dealers have mistakenly taken the position as constituting a Restructuring Credit Event.

${ }^{21}$ JPMorgan is one example.

${ }^{22}$ Due to differences in regulation, the European markets adopt a different type of restructuring: "ModifiedModified Restructuring" that allows the maturity of of the restructured bond or loan to go up to 60 months after the restructuring date.
} 
settlement, in which the buyer delivers the physical security while the seller pays the buyer the face value of the referenced security; and (2) a cash settlement, in which the seller simply settles the difference between the market value of the defaulted security and its face value. Physical settlement seems to be a prevalent choice even though the purchaser of a $C D S$ contract is not required to hold the physical security when entering into the contract ${ }^{23}$.

Finally, more than 95 percent of the $C D S$ contracts in Fitch Rating's Valuspread database refer to senior unsecured obligations by the underlying issuers. Thus, recovery information implicit in these contracts corresponds to firms' senior unsecured bonds. This feature of the $C D S$ market thereby facilitates meaningful comparison of recovery rates across firms since seniority and security levels of the underlying obligations are almost always held constant.

\section{A general derivative pricing model in the presence of defaults}

Before going into details, to facilitate intuition let's consider a simple one-period trinomial setting, as illustrated in Figure 1, where time unit is normalized to one year. The stock price is currently $S_{0}$. Next period, it can either go up to $S_{1}^{u}$, down to $S_{1}^{d}$ or jump to a default-value of 0 . Assume further that we know $S_{1}^{u}$ and $S_{1}^{d}$ but not the probabilities $p^{u}$ and $p^{d}$. At the same time, a call option on the same stock with one period to maturity and strike price $\mathrm{X}$ is selling for $c_{0}$. If the risk-free interest rate is constant at $r$, discounting the expected payoffs under the pricing measure must give the prices of both the derivative and the underlying:

$$
\begin{aligned}
e^{-r}\left(p^{u} c_{1}^{u}+p^{d} c_{1}^{d}\right) & =c_{0} \\
e^{-r}\left(p^{u} S_{1}^{u}+p^{d} S_{1}^{d}\right) & =S_{0}
\end{aligned}
$$

From these equations we can solve for probabilities $p^{u}$ and $p^{d}$ that are consistent with both prices. These probabilities are risk-neutral and can be used to price any derivative contract conditioning on the underlying stock. A $C D S$ contract that pays $\$ 1$ to buyers in exchange for a physical delivery of the firm's bond with normalized face value of $\$ 1$ contingent on the firm's default will be worth $e^{-r}\left(1-p^{u}-p^{d}\right) L^{\mathbb{Q}} . L^{\mathbb{Q}}$ is the fractional loss in face value of the bond and represents the net payment from the seller to the buyer of the $C D S$ contract when a credit event is triggered. If the $C D S$ contract is trading at a premium of, say, $\varphi$ basis points then, under this setting, it implies a risk neutral loss given default rate of:

$$
L^{\mathbb{Q}}=\frac{e^{r} \varphi / 10000}{1-p^{u}-p^{d}}
$$

Interestingly and perhaps not surprisingly, the same intuition carries into a more general setting. Generally, if the evolution of equity prices can be described in a lattice framework,

\footnotetext{
${ }^{23}$ This could create a situation similar to that of Delphi's default where the notional amount underlying the Delphi-CDS contract in circulation is significantly more than the outstanding face value of the underlying bonds.
} 


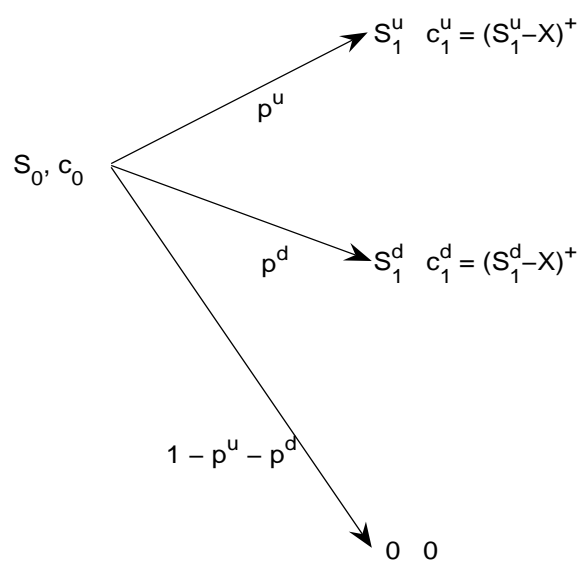

Figure 1 Trinomial Example

option prices or any derivative prices with zero recovery and similar terminal conditions can be overlaid to that framework to recover unknown parameters of the equity process. These parameters are risk-neutral in nature and consistent with both sets of equity prices and option (or derivative) prices. Once the parameters are estimated, the default dynamics of the underlying equity is fully known. In pricing other derivative contracts whose expected recovery conditional on default is non-zero, the only unknown is the recovery information itself. Thus, given a set of prices of these contracts, it should be possible to learn about the recovery information pertaining to these contracts.

In what follows, I will describe the basic elements of the pricing framework using continuoustime notation for ease of presentation. Next, I will illustrate how the framework can be discretized into a lattice and how pricing of options and $C D S$ contracts can be performed along this lattice.

\subsection{The building blocks}

The three building blocks of this pricing framework are: (1) a stochastic process governing the dynamics of the spot rates; (2) a stochastic process governing the evolution of equity price; (3) a hazard function governing equity's propensity to jump to default per unit of time - all under the risk-neutral measure $\mathbb{Q}$. Default occurs when equity prices jump or diffuse to zero. Borrowing continuous-time notation, these three building blocks can be represented 
as follows:

$$
\begin{aligned}
\text { Short rate dynamics: } & d r_{t}=\mu^{r}\left(r_{t}\right) d t+\sigma^{r}\left(r_{t}\right) d B_{t}^{\mathbb{Q} r} \\
\text { Equity dynamics: } & \frac{d S_{t}}{S_{t}}=\left(r_{t}+h\left(r_{t}, S_{t}\right)\right) d t+\sigma^{S}\left(S_{t}\right) d B_{t}^{\mathbb{Q} s}-\left(d N_{t}^{\mathbb{Q}}-h\left(r_{t}, S_{t}\right) d t\right) \\
\text { Hazard function: } & h\left(r_{t}, S_{t}\right)
\end{aligned}
$$

where $s$ and $r$ superscripts refer, respectively, to the equity and the short rate. $d B^{\mathbb{Q} s}$ and $d B^{\mathbb{Q} r}$ are independent standard Brownian innovations ${ }^{24} . d N_{t}^{\mathbb{Q}}$ is a Poisson counting process with intensity $h\left(r_{t}, S_{t}\right) . N_{t}^{\mathbb{Q}}$ only counts until 1 at which point the firm jumps to default and its equity price collapses to zero. Since prior to default, $N_{t}^{\mathbb{Q}}=0$, I can write the pre-default equity process as follows:

$$
\frac{d S_{t}}{S_{t}}=\left(r_{t}+h\left(r_{t}, S_{t}\right)\right) d t+\sigma^{S}\left(S_{t}\right) d B_{t}^{\mathbb{Q} s}
$$

I assume that $S_{t}$ and $r_{t}$ are the only two state variables in this environment although the functional forms of their conditional moments and the dependence of the hazard function on these two variables can be general, subject to no-arbitrage conditions and some technicalities to ensure feasibility in building a recombining lattice.

The short rate $r_{t}$ can, for example, take on the Vasicek (1977) or Cox, Ingersoll, and Ross (1985) (CIR)'s specifications in which both the conditional drifts and the conditional variances of the short rate are linear functions of the short rate itself. $r_{t}$ can also take the three-halves formulation developed by Ahn and Gao (1999) who specify the drift and the volatility terms to be nonlinear in $r_{t}$. Though it is possible to represent a multi-factor shortrate process in a lattice, to keep the lattice practically feasible, I will restrict $r_{t}$ to the case of a single-factor process. For illustrative purposes, it is instructive to adopt a particular specification for the short rate $r_{t}$. Therefore, in the next subsection I will assume $r_{t}$ to follow a standard $C I R$ process:

$$
d r_{t}=\kappa^{\mathbb{Q}}\left(\theta^{\mathbb{Q}}-r_{t}\right) d t+\sigma \sqrt{r_{t}} d B_{t}^{\mathbb{Q} r}
$$

As for the equity process, the conditional volatility term can be general. Common choices include setting $\sigma^{S}\left(S_{t}\right)$ to a constant or setting $\sigma^{S}\left(S_{t}\right)$ to a negative power of stock price: $\sigma\left(S_{t}\right)=\sigma S_{t}^{-\beta}$ where $\beta$ is a non-negative constant, typically less than 1 . Whereas the former choice is consistent with a log-normal diffusion, the latter corresponds to the Constant Elasticity of Variance $(C E V)$ specification. If $S_{t}$ follows a log-normal process, equity prices can only jump to default through the Poisson dynamics. The $C E V$ specification however allows the stock price to hit zero through both channels: the diffusion and the Poisson forces. In addition, as long as $\beta>0$, the $C E V$ setup also accounts for the leverage effect - a well known empirical observation that as equity prices decrease, leverage of the underlying firm is higher, which in turn makes the stock riskier and hence more volatile.

Alternatively, $\sigma^{S}\left(S_{t}\right)$ can take the following form: $\sigma\left(1+D S_{t}^{-1}\right)$ where $\sigma$ and $D$ are positive constants. This specification of $\sigma^{S}\left(S_{t}\right)$ can be seen as a weighted average between

\footnotetext{
${ }^{24}$ The assumption of zero conditional correlation between $d B_{t}^{\mathbb{Q} r}$ and $d B_{t}^{\mathbb{Q} s}$ is just for the ease of exposition and can be easily relaxed - detailed treatment is provided in Acharya and Carpenter (2002)
} 
the two polar cases of the $C E V$ specifications when $\beta=0$ and $\beta=1$. Intuitively, this choice of $\sigma^{S}\left(S_{t}\right)$ relates to a simple structural setting in which the firm's asset value $V_{t}$ follows a Geometric Brownian Motion with a constant volatility $\sigma$ while the firm's market debt value is constant at D and serves as the default threshold for the firm's asset. In this setting, equity value is simply the difference between asset value and market value of debt $S_{t}=V_{t}-D$. Since the diffusion part of $\frac{d V_{t}}{V_{t}}$ is $\sigma d B_{t}$, it follows that the diffusion part of $\frac{d S_{t}}{S_{t}}$ must be $\sigma \frac{V_{t}}{S_{t}} d B_{t}=\sigma\left(1+D S_{t}^{-1}\right) d B_{t}$. This choice of modeling equity is referred to as the Translated Geometric Brownian motion and is considered in Das and Sundaram (2003) and underlies the industry E2C's model used by JPMorgan. In any event, when building the lattice in the next subsection, I will adopt the $C E V$ specification for illustrative purposes.

Many specifications have been proposed in modeling the hazard function. For instance, Samuelson (1972) and Hull, Nelken, and White (2004) assume the default intensity $h(.,$.$) to$ be a constant while letting stock prices follow a log-normal diffusion. Campi, Polbennikov, and Sbuelz (2005) also assume a constant hazard rate but allow equity prices to follow a $C E V$ process. Linetsky (2006) models $h($.$) as a negative power of the stock price h\left(S_{t}\right)=\alpha S_{t}^{-\gamma}$ with a constant variance rate for equity returns. Carr and Linetsky (2006) modifies this specification by having a $C E V$-type diffusion for equity prices and a hazard function which takes a linear transformation of the instantaneous variance $h\left(S_{t}\right)=\lambda+\alpha S_{t}^{-2 \beta}$, where $\beta$ is the $C E V$ coefficient. Das and Sundaram (2006) consider many other specifications including cases in which $h($.$) can take time and interest rate as inputs. Among these choices, Carr and$ Linetsky (2006)'s model nests many other specifications and yet still allows for analytical pricing. Thus, in the empirical implementation of this paper, this specification of the hazard function will be employed. However, for the sake of building the lattice, I will leave the hazard function in its general form.

\subsection{The lattice}

I employ the diffusion approximation technique developed by Nelson and Ramaswamy (1990) to discretize $r_{t}$ and $S_{t}$. The basic insight from Nelson and Ramaswamy (1990) is that: if the $\mathbb{Q}$-conditional volatilities of $r_{t}$ and $S_{t}$ take the normal or log-normal forms, binomial approximation with recombining nodes is straightforward. Therefore if there exist transform functions $f^{r}($.$) and f^{S}($.) such that after transformation, the transformed variables become normal or lognormal, one can build a lattice of the transformed processes $\left(f^{r}\left(r_{t}\right)\right.$ and $\left.f^{S}\left(S_{t}\right)\right)$ and then invert the transformed variables back to their original bases. The important feature of Nelson and Ramaswamy (1990)'s technique is the lattice's recombining property, which keeps computation to polynomial complexity ${ }^{25}$. At the same time, this technique ensures that the first two conditional moments of equity returns are recovered in the continuous-time limit. Due to Ito's lemma, if the diffusion term of $d r_{t}$ is $\sigma^{r}\left(r_{t}\right) d B_{t}^{\mathbb{Q} r}$ then $f\left(r_{t}\right)$ 's diffusion term will be: $f^{\prime}\left(r_{t}\right) \sigma^{r}\left(r_{t}\right) d B_{t}^{\mathbb{Q} r}$. Therefore, if there exists a function $f($.$) such that f^{\prime}\left(r_{t}\right) \sigma^{r}\left(r_{t}\right)$ becomes a constant and the inversion function $f^{-1}($.$) is well-defined, such a function can be$ used in the transformation step. In general, such a function can be found by solving the

\footnotetext{
${ }^{25}$ i.e. there are $\mathrm{N}+1$ final nodes for an $\mathrm{N}$-step tree
} 
indefinite integral $\int \frac{1}{\sigma^{r}(r)} d r$.

For illustrative purposes, the short rate has been assumed to follow a $C I R$ process and the equity process has the $C E V$ form in its diffusion. Therefore, the continuous-time processes of the two state variables, $r_{t}$ and $S_{t}$, are:

$$
\begin{aligned}
d r_{t} & =\kappa^{\mathbb{Q}}\left(\theta^{\mathbb{Q}}-r_{t}\right) d t+\sigma^{r} \sqrt{r_{t}} d B_{t}^{\mathbb{Q} r} \\
\frac{d S_{t}}{S_{t}} & =\left(r_{t}+h\left(r_{t}, S_{t}\right)\right) d t+\sigma^{S} S_{t}^{-\beta} d B_{t}^{\mathbb{Q} s}
\end{aligned}
$$

As can be easily checked, the transform functions for $r_{t}$ and $S_{t}$, respectively, are $f^{r}\left(r_{t}\right)=$ $\sqrt{r_{t}}$ and $f^{S}\left(S_{t}\right)=S_{t}^{\beta}$. Letting the discrete time interval be $\Delta t$, the discretization process, starting from a node characterized by a short rate $r_{t}$ and a stock price $S_{t}$, can proceed as follows:

$$
\begin{array}{r}
r_{t+\Delta t}=\left\{\begin{array}{l}
\left(\sqrt{r_{t}}+\frac{1}{2} \sigma^{r} \sqrt{\Delta t}\right)^{2} \text { with probability } p^{r}=\frac{e^{\mu^{r} \Delta t}-e^{-\sigma^{r} \sqrt{\Delta t}}}{e^{\sigma^{r} \sqrt{\Delta t}}-e^{-\sigma^{r} \sqrt{\Delta t}}} \\
\left(\sqrt{r_{t}}-\frac{1}{2} \sigma^{r} \sqrt{\Delta t}\right)^{2} \text { with probability } 1-p^{r}
\end{array}\right. \\
\text { where } \mu^{r}=\left(\kappa^{\mathbb{Q}} \theta^{\mathbb{Q}}-\frac{1}{4}\left(\sigma^{r}\right)^{2}\right) \frac{1}{\sqrt{r_{t}}}-\kappa^{\mathbb{Q}} \sqrt{r_{t}}+\frac{1}{2}\left(\sigma^{r}\right)^{2}
\end{array}
$$

and

$$
\begin{aligned}
& S_{t+\Delta t}=\left\{\begin{array}{l}
\left(S_{t}^{\beta}+\sigma^{S} \beta \sqrt{\Delta t}\right)^{\frac{1}{\beta}} \text { with probability } p^{S}=\frac{e^{\mu^{S} \Delta t}-e^{-\sigma^{S} \sqrt{\Delta t}}}{e^{\sigma^{S} \sqrt{\Delta t}}-e^{-\sigma^{S} \sqrt{\Delta t}}} \\
\left(S_{t}^{\beta}-\sigma^{S} \beta \sqrt{\Delta t}\right)^{\frac{1}{\beta}} \text { with probability } 1-p^{S}
\end{array}\right. \\
& \text { where } \mu^{S}=S_{t}^{\beta}\left(r_{t}+h\left(r_{t}, S_{t}\right)\right)+\frac{1}{2}(\beta-1)\left(\sigma^{S}\right)^{2} S_{t}^{-\beta}+\frac{1}{2}\left(\sigma^{S}\right)^{2}
\end{aligned}
$$

Note that $r_{t}$ must be positive and $S_{t}$ must be non-negative. Therefore, the lower branches of the tree will be truncated at zero. To compensate for the bias caused by this truncation, Nelson and Ramaswamy (1990) suggest that lower nodes of the tree should take multiple steps upwards. Details of this process are covered in Nelson and Ramaswamy (1990) or the appendix of Acharya and Carpenter (2002). Since the trees are recombining, starting from $S_{0}$ and $r_{0}$, after $N$ steps there will be $N+1$ different values for $S_{t+(N+1) \Delta t}$, and $N+1$ different values for $r_{t+(N+1) \Delta t}$. Combining the two trees results in $(N+1)^{2}$ different pairs of $\{S, r\}$. The probabilities of these pairs can be computed iteratively at each step. The details of this computation is provided in Appendix A. Finally, the independence assumption between equity returns innovations and short rate innovations have made construction of the lattice straightforward. However, it is possible to model instantaneous correlations of the two innovations by first linearly rotating the pairs $\left(r_{t}, S_{t}\right)$ until they become orthogonal ${ }^{26}$.

\footnotetext{
${ }^{26}$ For details, readers are referred to Acharya and Carpenter (2002).
} 


\subsection{Valuation of call options}

With the two-dimensional binomial tree constructed above, from a node $\left\{S_{t}, r_{t}\right\}$ at time $\mathrm{t}$, there will generally be 5 branches extending out to time $t+\Delta t$, one of which corresponds to the jump-to-default state. The other four branches correspond to 4 different combinations of $\left\{S_{t+\Delta t}, r_{t+\Delta t}\right\}$ as specified in equations (8) and (10). Equations (8) and (10) also provide the probabilities of each of these branches occurring. For a general equity process, such as the $C E V$ specification, stock price can be absorbed at zero simply due to the diffusion forces. The default probabilities at the lowest branch of the tree (where the next downward movement triggers default) therefore include both the sudden types of defaults and the diffusion types of defaults. Upper in the tree, default mechanism can only be caused by the Poisson dynamics. If any of these four branches corresponds to an equity price of zero, it effectively coincides with a default state. As such, starting from a node $\left\{S_{t}, r_{t}\right\}$ at time t, the number of non-default states $\mathrm{M}$ at time $t+\Delta t$ may be less than 4 . Let $\left\{S^{1}, r^{1}\right\},\left\{S^{2}, r^{2}\right\}$ $\ldots$ and $\left\{S^{M}, r^{M}\right\}$ denote the $M$ non-default pairs of $\{S, r\}$ at time $t+\Delta t$ and $p^{1}, p^{2}, \ldots p^{M}$ denote their corresponding probabilities. The total probability of default, which include both default types, is: $p^{d}=1-\sum_{1}^{M} p^{i}$. Let's $c(S, r, T)$ denote the value of a call option with an underlying price of $S$, a short-rate $r$ and a maturity $T$ at some exercise price $K . c(S, r, T)$ can be computed along the lattice in the standard way:

$$
\begin{aligned}
c(S, r, 0) & =\max (S-K, 0) \\
c\left(S_{t}, r_{t}, j \Delta t\right) & =e^{-r_{t} \Delta t}\left[\sum_{1}^{M} p^{i} c\left(S^{i}, r^{i},(j-1) \Delta t\right)\right] \text { if } S_{t}>0 \\
c\left(S_{t}, r_{t}, j \Delta t\right) & =0 \text { if } S_{t}=0
\end{aligned}
$$

where implicit in the last two equations is the assumption of zero recovery for call options. Since call options are not protected against default, even if equity is still traded after a default event, its defaulted value may render most call options (except for those with very low strike prices) far out of the money and valueless.

\subsection{Computing $C D S$ spreads}

As described in section 2, credit default swap contracts are insurance contracts on bonds' defaults. The insurance buyer keeps paying a premium $c_{0}$ until the contract expires or until the bond issuer defaults on bond payments in which case the insurance seller gives the buyer the par value of the bond in exchange for the defaulted bond. At the start of the contract, $c_{0}$ is determined by equating the prices of the cash flows coming from the two parties.

Using continuous-time notation, the present value of the stream of premium payments for a $C D S$ contract with maturity $\mathrm{T}$ is:

$$
\text { Premium }=c_{0} E^{\mathbb{Q}}\left[\int_{0}^{T} e^{-\int_{0}^{t} r_{s} d s} Q(\tau>t) d t\right]
$$


where $\tau$ defines the time of default and $\mathbb{Q}$ denotes probability measure under the pricing measure. Along the lattice, the above integration can be discretized as follows:

$$
\begin{aligned}
\operatorname{pre}(S, r, 0) & =0 \\
\operatorname{pre}\left(S_{t}, r_{t}, j \Delta t\right) & =c_{0} \Delta t+e^{-r_{t} \Delta t}\left[\sum_{1}^{M} p^{i} \operatorname{pre}\left(S^{i}, r^{i},(j-1) \Delta t\right)\right] \text { if } S_{t}>0 \\
\operatorname{pre}\left(S_{t}, r_{t}, j \Delta t\right) & =0 \text { if } S_{t}=0
\end{aligned}
$$

where $\operatorname{pre}(S, r, T)$ denotes the risk neutral expected present value of the series of premium payments $^{27}$ with a horizon $\mathrm{T}$, starting from a node in the tree where equity and short rate are $\{S, r\}$.

Regarding the protection payment, the present value of the payment from the insurance provider is:

$$
\text { Protection }=-E_{0}^{\mathbb{Q} s}\left[\int_{0}^{T} L_{t}^{\mathbb{Q}} e^{-\int_{0}^{t} r_{s} d s} d Q(\tau>t)\right]
$$

Computation of the right-hand side of equation (19) depends on the recovery assumption of $L^{\mathbb{Q}}$. The simplest case is where $L^{\mathbb{Q}}$ corresponds to the Recovery of Face Value assumption. Though it is possible and quite straightforward to allow for the Recovery of Market Value or the Recovery of Treasury assumption in this setting, the Recovery of Face Value assumption seems to relate most closely to how a $C D S$ contract works. Therefore, I will only consider pricing of a $C D S$ contract under the Recovery of Face Value assumption here. In this case, if $\operatorname{pro}(S, r, T)$ defines the risk neutral expected present value of protection payment within a horizon $\mathrm{T}$, starting from a node $\{S, r\}$, it can be computed iteratively along the lattice as follows:

$$
\begin{aligned}
\operatorname{pro}(S, r, 0) & =0 \\
\operatorname{pro}\left(S_{t}, r_{t}, j \Delta t\right) & =e^{-r_{t} \Delta t}\left[\sum_{1}^{M} p^{i} \operatorname{pro}\left(S^{i}, r^{i},(j-1) \Delta t\right)+p^{D} L_{t}^{\mathbb{Q}}\right] \text { if } S_{t}>0 \\
\operatorname{pro}\left(S_{t}, r_{t}, j \Delta t\right) & =L_{t}^{\mathbb{Q}} \text { if } S_{t}=0
\end{aligned}
$$

As can be seen, the dynamics of $L^{\mathbb{Q}}$ can be quite flexible. For instance, if a researcher would like to directly model the relationship between $L^{\mathbb{Q}}$ and the jump-to-default rates, one possibility is to set $L_{t}^{\mathbb{Q}}=a_{0}+a_{1} \times h\left(r_{t}, S_{t}\right)$. In this simple formulation, coefficient $a_{1}$ will govern the correlation between the loss rate and the default arrival intensity. In addition, $L^{\mathbb{Q}}$ can also contain exogenous noise - information that is specific to loss rates only. One way to model these noises is to write $L^{\mathbb{Q}}$ as a product of two independent terms: $w_{t} g(S, r)$

\footnotetext{
${ }^{27}$ Note that premiums on single-name $C D S$ contracts are typically paid every quarter. It is assumed that the premium is paid continuously here for ease of presentation. However, the actual frequency of premium payments can be easily accommodated in the current lattice.
} 
where the function $g(S, r)$ captures the part that $L^{\mathbb{Q}}$ is related to the equity price and the short rate. This way, the integration of $w_{t}$ can be done separately as follows:

$$
\text { Protection }=-E_{0}^{\mathbb{Q}}\left[w_{t}\right] E_{0}^{\mathbb{Q}}\left[\int_{0}^{T} g(S, r) e^{-\int_{0}^{t} r_{s} d s} d Q(\tau>t)\right]
$$

Depending on the assumption of how $w_{t}$ evolves $^{28}, E_{0}^{\mathbb{Q}}\left[w_{t}\right]$ can be computed as a function of $w_{0}$.

\subsection{A special case with closed-form solutions}

To facilitate fast computation in cross-sectional analysis, in the remaining part of the paper I will specialize to a specific setup of the above framework where analytical option prices and $C D S$ premiums are feasible by applying results from Carr and Linetsky (2006). In particular, the interest rate will be assumed to be a constant while the pre-default equity process and the hazard function will take the following form:

$$
\begin{aligned}
h\left(S_{t}\right) & =b+c \sigma^{2} S_{t}^{-2 \beta} \\
\frac{d S_{t}}{S_{t}} & =\left(r+h\left(S_{t}\right)\right) d t+\sigma S^{-\beta} d B_{t}^{\mathbb{Q} s}
\end{aligned}
$$

where $b, c, \beta$ are non-negative constants, $\sigma$ is positive and $\beta$ is less than or equal to 1 . In this setup, if $c$ is strictly positive then the hazard function is effectively a linear transformation of the conditional variance of equity returns.

\subsection{Option pricing}

With this setup, Carr and Linetsky (2006) show that American call option on non-dividend paying stocks with maturity $\mathrm{T}$ and exercise price $\mathrm{K}$ can be priced as follows:

$$
C(S, T, K)=S \Phi\left(0, \frac{k^{2}}{\tau} ; \delta_{+}, \frac{x^{2}}{\tau}\right)-K\left(\frac{x^{2}}{\tau}\right)^{\frac{1}{2 \beta}} \Phi\left(-\frac{1}{2 \beta}, \frac{k^{2}}{\tau}, \delta_{+}, \frac{x^{2}}{\tau}\right)
$$

where

$$
\begin{aligned}
x & =\frac{1}{\beta} S^{\beta} \\
\tau & =\frac{\sigma^{2}}{2 \beta(r+b)}\left(1-e^{-2 \beta(r+b) T}\right) \\
k & =\frac{1}{\beta} K^{\beta} e^{-\beta(r+b) T} \\
\delta_{+} & =\frac{2 c+1}{\beta}+2
\end{aligned}
$$

\footnotetext{
${ }^{28}$ For example, one can write $w_{t}=e^{-x_{t}}$ where $x_{t}$ follows a $C I R$ process. In this case, $E_{0}\left[w_{t}\right]$ can be computed analytically.
} 
and

$$
\Phi(p, k ; \delta, \alpha)=2^{p} \sum_{n=0}^{\infty} e^{-\frac{\alpha}{2}}\left(\frac{\alpha}{2}\right)^{n} \frac{\Gamma\left(\frac{\delta}{2}+p+n, \frac{k}{2}\right)}{n ! \Gamma\left(\frac{\delta}{2}+n\right)}
$$

where $\Gamma($.$) is the standard Gamma function and \Gamma(.,$.$) is the complementary incomplete$ Gamma function.

The above formula involves summing up an infinite series. Theoretically, this series is convergent. In fact, if the value of $\frac{x^{2}}{\tau}$ is small, the sum converges relatively fast. However, convergence is very slow for large values of $\frac{x^{2}}{\tau}$, which correspond to cases where the maturity $\mathrm{T}$ is short; the $C E V$ coefficient $\beta$ is close to 0 ; or the volatility parameter $\sigma$ is small. These are cases in which the equity process approaches the log-normal diffusion. To overcome this issue, I adopt the following scheme:

- If $\frac{x^{2}}{\tau}<1000$, equation (26) will be employed. The infinite series in equation (31) will be approximated by the first 1000 terms. Adding more than 1000 terms are unlikely to change option prices over a large range of parameters.

- if $\frac{x^{2}}{\tau} \geq 1000$, the equity process will be approximated as a log-normal process where the conditional volatility is set at $\sigma S_{0}^{-\beta}$ and $\beta$ is set at zero.

To ensure that this computational scheme is reliable, I compare prices computed according to this scheme and prices computed from one million simulations using the same parameters. The results are reported in Table 1. Prices are computed for options on stock trading at $\$ 10$, with exercise prices $\$ 8, \$ 10, \$ 12$ and risk-free interest rate of $2 \%$ and with varying values for other parameters. As can be seen, pricing errors are very small, often less than 1 cent regardless of parameters values.

\subsection{Risk-neutral survival probability}

Given the above set-up, Carr and Linetsky (2006) show that risk-neutral survival probability $Q(S, T)$ within time $T$ for an equity process starting at $\mathrm{S}$ can be computed by the following formula:

$$
Q(S, T)=e^{-b T}\left(\frac{x^{2}}{\tau}\right)^{\frac{1}{2 \beta}} M\left(-\frac{1}{2 \beta} ; \delta_{+}, \frac{x^{2}}{\tau}\right)
$$

where the $\mathrm{M}(., .,$.$) function is defined as follows:$

$$
M(p ; \delta, \alpha)=2^{p} e^{-\frac{\alpha}{2}} \frac{\Gamma\left(p+\frac{\delta}{2}\right)}{\Gamma\left(\frac{\delta}{2}\right)}{ }_{1} F_{1}\left(p+\frac{\delta}{2}, \frac{\delta}{2}, \frac{\alpha}{2}\right)
$$

where ${ }_{1} F_{1}$ denotes the Kummer confluent hypergeometric function:

$$
{ }_{1} F_{1}(a, b, x)=\sum_{n=0}^{\infty} \frac{(a)_{n}}{(b)_{n}} \frac{x^{n}}{n !}
$$




\section{Table 1}

\section{Option Pricing Performance}

Call option prices and risk-neutral default probabilities are computed, under various parameter assumptions, using (1) one million simulations; and (2) the analytical pricing scheme whose full details are described in section 3.6 and section 3.7 of the paper. Equity prices follow:

$$
\frac{d S_{t}}{S_{t}}=\left(r+b+c \sigma^{2} S_{t}^{-2 \beta}\right) d t+\sigma S^{-\beta} d B_{t}^{\mathbb{Q} s}
$$

where $b, c$ are non-negative; $\sigma$ is positive and $\beta$ is within the unit interval. The underlying stock price at time 0 is $\$ 10$. Risk-free interest rate is constant at $2 \% . \sigma_{0}$, computed as $\sigma S_{0}^{-\beta}$, is the conditional volatility of equity returns at time $0 . \mathrm{QD}$ denotes the risk-neutral probability of default. $\mathrm{T}, \mathrm{X}$ denote, respectively, the maturity and the strike price of an option. Lines starting with QD contain default probabilities for a given set of parameters. Lines starting with exercise prices $(X=8, X=10, X=12)$ contain option prices. Simulated prices and probabilities are reported in columns with heading "Sim.". Model prices and probabilities are reported in columns with heading "Mod.".

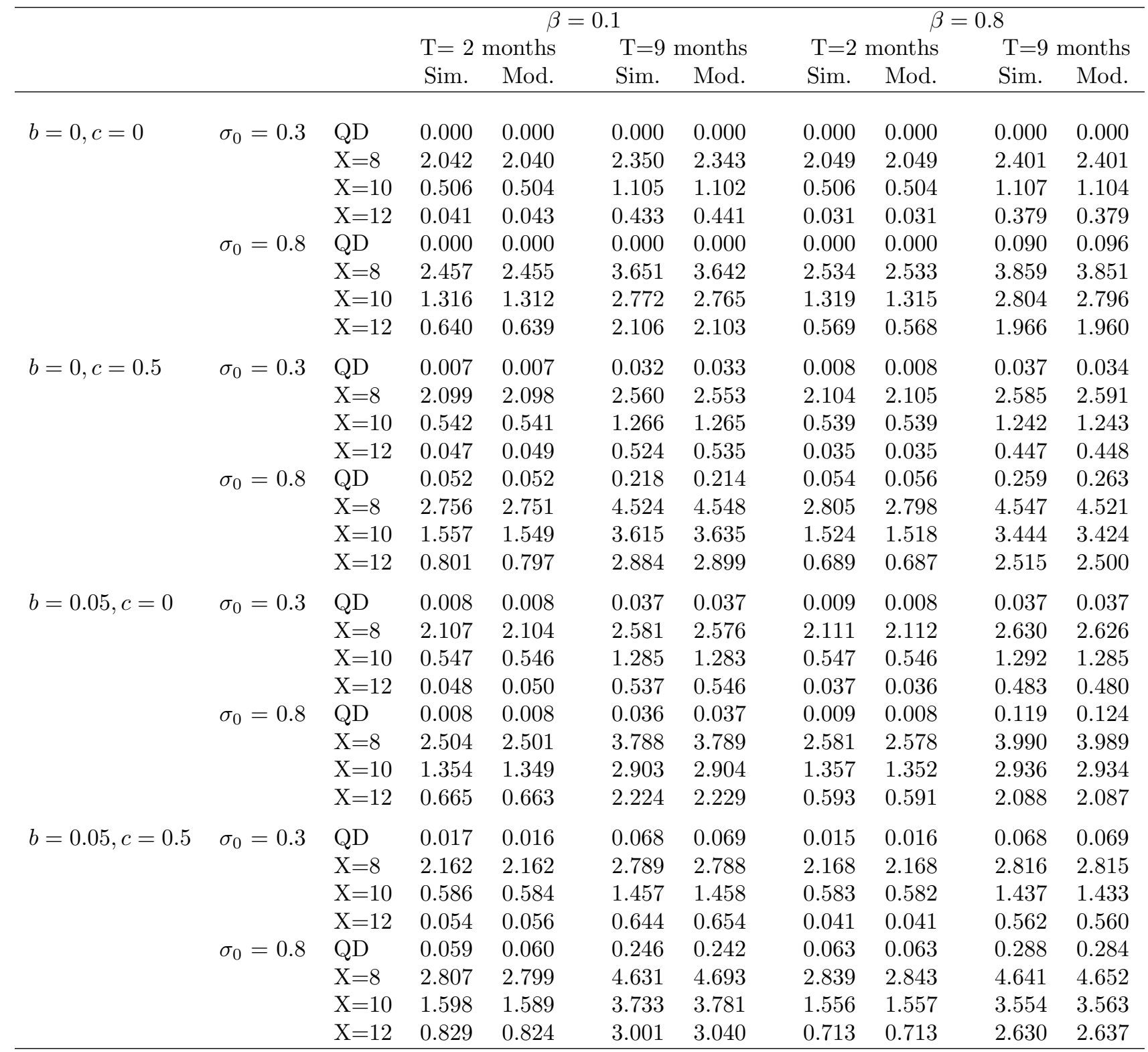


and $(a)_{0}=0,(a)_{n}=a(a+1) \ldots(a+n-1), n>0$.

As with option pricing, the risk-neutral survival probability formula in equation (32) also has difficulties converging for large values of $\frac{x^{2}}{\tau}$. To this extent, I will adopt a similar scheme in computing $Q(S, T)$ :

- If $\frac{x^{2}}{\tau}<1000$, equation (32) will be used;

- if $\frac{x^{2}}{\tau} \geq 1000$, the hazard rate will be assumed constant at $b+c \sigma^{2} S_{0}^{-2 \beta}$ and $\beta$ will be set to zero, after which equation (32) will be applied.

Table 1 compares simulated default probabilities (using 1 million simulations for each set of parameters) to the model's default probabilities with the same parameters as given above and shows that this scheme delivers quite accurate default probabilities - magnitude of average absolute errors is less than .1\%.

\section{$3.8 C D S$ pricing}

Given this setup, for a reference entity with current equity price standing at $\mathrm{S}$, a $C D S$ contract with quarterly ${ }^{29}$ premium payments on a bond with $\$ 1$ face value and constant fractional loss $L^{\mathbb{Q}}$ on default can be priced as follows:

$$
\frac{1}{4} C D S_{t}(M) \sum_{j=1}^{4 M} e^{-\frac{1}{4} j \times r} Q\left(S, \frac{1}{4} j\right)=L^{\mathbb{Q}} \int_{0}^{M} e^{-r t} d Q(S, t)
$$

The left-hand side represents the discounted present values of the $C D S$ premium payments accounting for the probability that the firm survives at the time the payments are due. The right-hand side is the discounted expected protection payment from the $C D S$ issuer in default. In computing the integration on the right hand side, I will discretize the integration into daily intervals and approximate $d Q(S, t)$ by the difference of survival probabilities for two consecutive days. That is,

$$
\frac{1}{4} C D S_{t}(M) \sum_{j=1}^{4 M} e^{-\frac{1}{4} j \times r} Q\left(S, \frac{1}{4} j\right)=L^{\mathbb{Q}} \sum_{i=0}^{365 \times M} e^{-r \times \frac{i}{365}}\left(Q\left(S, \frac{i}{365}\right)-Q\left(S, \frac{i+1}{365}\right)\right)
$$

\section{Data and summary statistics}

\subsection{Options data}

Option end-of-day quotes and their underlying stock prices are obtained from Option Metrics, covering a period from January 1996 to June 2005. I apply several filters to the original data set. First, I choose only call option data on non-dividend paying stocks. This way,

\footnotetext{
${ }^{29}$ This is the standard payment frequency for $C D S$ contracts on corporate bonds. Sovereign $C D S$ has a semi-annual payment frequency.
} 


\section{Table 2}

\section{Summary Statistics of Option Data}

Call options are obtained from Option Metrics from Jan 1996 - June 2005. The following options are excluded: (1) options with maturities less than 30 days or more than 1 year; (2) options with zero open interest; (3) options on stocks that pay dividends within their maturities; (4) options on stocks with prices less than $\$ 5$; (5) options too far away from the money $(|\ln (S / K)|>30 \%)$ - where $\mathrm{S}$ and $\mathrm{K}$ are, respectively, the underlying stock price and the strike price of the options. (6) options with a bid-ask spread greater than 50 percent of the option's price. Options' moneyness is measured as $\ln (S / K)$, expressed in percentage.

\begin{tabular}{lcccc}
\hline & & $5^{t h}$ & $95^{t h}$ \\
& Mean & Median & Percentile & Percentile \\
\hline & & & & \\
Maturity (days) & 110.13 & 96.00 & 32.00 & 222.00 \\
Moneyness (\%) & -0.05 & -0.30 & -24.42 & 24.71 \\
Open interest & 703.96 & 100.00 & 4.00 & $2,821.00$ \\
Observations per firm-month & 108.03 & 85.00 & 6.00 & 288.00 \\
\hline
\end{tabular}

analytical pricing of American call options is straightforward without the need for dividend adjustments $^{30}$. Second, I choose only options that have positive open interest as a proxy for liquidity. Other authors such as Ofek, Richardson, and Whitelaw (2004) have used open interest as a proxy for liquidity in the option markets. ${ }^{31}$ Third, only options with maturity of less than one year and more than one month are included. Options with less than one month to maturity often have little time-value and thus contain less information about the future dynamics of the underlying firm. Options with long maturities are highly illiquid. Fourth, options with underlying stocks quoted for less than $\$ 5$, options that are too far away from the money $(|\ln (S / K)|>0.3)$, options that have a bid-ask spread that is greater than 50 percent of the option price (mid point) are also eliminated. These options are either illiquid or likely to contain recording errors. Summary statistics of the final set of options are provided in Table 2.

\section{2 $C D S$ data}

$C D S$ data are obtained from Fitch Ratings' ValuSpread. This database provides mean market quotes for more than 2500 reference entities that goes back to July 1999. For an observation to be included, several requirements must be met. First, daily mean $C D S$ premium has to be less than 5000 basis points. Firms with a $C D S$ premium larger than 5000 basis points are often already in default or effectively out of the $C D S$ markets. Second, only quotes specific to senior debts (which accounts for 95 percent of the database) are in-

\footnotetext{
${ }^{30}$ There is no closed form formula for American put option even on non-dividend-paying stocks. However, the lattice approach developed in the previous section can price American put options regardless of whether the underlying stocks pay dividends or not. I choose the analytic formula to optimize computing time.

${ }^{31}$ This also ensures that option quotes cannot be too far away from their true values even during nontrading days.
} 
cluded. Third, all contracts denominated in foreign currencies or contracts that condition on a restructuring type other than "Modified Restructuring" are excluded. "Modified Restructuring" is the standard contract type for North American reference entities ${ }^{32}$. The original data start from 30 July 1999 but after the above initial trimming, all quotes prior to 19 September 2001 are eliminated.

Since the only identifiers in ValuSpread are company names and ValuSpread's ticker codes, when matching ValuSpread companies to other databases such as Option Metrics, CRSP or COMPUSTAT, I require that company names from different sources be exactly the same, after allowing for possible abbreviations (such as Corp. and Corporation). If a company changes its name, documentation of this change must be found in either the Factiva or the Hoover Online database. Finally, two companies from different databases can also be matched if one is the main operating unit of the other ${ }^{33}$. Out of 2162 names surviving after the initial pruning, 1377 names can be matched with CRSP permnos and COMPUSTAT gvkeys. Non-matched observations are mostly foreign names, sovereign quotes, private firms or whole subsidiaries of listed companies. Panel A of Table 3 provides summary statistics of $C D S$ data and the characteristics of their underlying firms. Panel $\mathrm{B}$ of Table 3 reports the same statistics for the sample of firms whose corresponding option data can be found.

\subsection{Default and ratings data}

Default data are put together from four sources: Moody's Default Risk Service, Compustat Footnote, Altman's bankruptcy list and data from BankruptcyData.Com. These four sources complement and confirm each other. None of these lists is completely nested by any other. Compustat footnotes (data items AFTNT35, AFTNT34 and AFTNT33 respectively) provide code of deletion and the year and month of deletion. Code of deletion runs from 1 to 10 with 2 and 3 corresponding to bankruptcy under Chapter 11 and Chapter 7 respectively. However, the deletion year and month refer to the date a stock is dropped from the COMPUSTAT database; thus actual default date can be before or after this deletion date. Therefore, to reliably identify the date when default occurs, if the same default can be identified from the other 3 sources, COMPUSTAT's deletion date will not be used. COMPUSTAT's deletion date will be used as a default date only when information from the other 3 sources is absent.

Moody's Default Risk Service provides detailed issue and issuer information on ratings, default and bankruptcies, starting from 1938 to now. In this paper, the following categories in Moody's Default Risk Service database are classified as defaults: Bankruptcy, Bankruptcy Section 77, Chapter 10, Chapter 11, Prepackaged Chapter 11, distressed exchange, dividend omission, grace-period default, indenture modified, missed interest payment, missed principal and interest payments, missed principal payment, payment moratorium, suspension of payments. It should be noted that the above criteria of defaults match relatively well with

\footnotetext{
${ }^{32}$ Full definition details of the restructuring rules of credit protection can be found at www.isda.org

${ }^{33}$ Property trusts typically fall into this category since it is a standard practice for property trusts to set up a main operating unit (often with a very similar name), fully responsible for day-to-day running of the trusts. For example, Highwoods Properties is the main operating unit of Highwood Realty, therefore will be deemed the same as Highwood Realty for database-matching purposes.
} 


\section{Table 3}

\section{Summary Statistics of $C D S$ Data}

Panel A presents summary statistics of ValuSpread's $C D S$ data for all firms in the sample from 2002 to 2005. $C D S 1, C D S 3$ and $C D S 5$ are, respectively, $C D S$ premiums, in basis points, with 1, 3 and 5 year(s) to maturity. Market Cap is firms' total market capitalization, in millions of dollars. Leverage is computed as debt/(debt + market cap). BTM is the book-to-market ratio, computed as (asset-debt)/market cap. Asset and debt (long-term debt + short-term debt) are book values and obtained, when available, from the COMPUSTAT quarter and annual files. Price and shares outstanding data (in computing market cap) are obtained from the CRSP file. Panel B presents the same statistics of $C D S$ data for firms that have options coverage during the same month. Panel $\mathrm{C}$ reports the distribution of ratings for samples of firms used in Panel A and B. Ratings data are obtained from Moody's Default Risk Service. These ratings are estimated by Moody's in such a way that they correspond to senior classes of debts - the same classes of debts underlying ValuSpread's $C D S$ contracts used in the sample.

Panel A: All firms

\begin{tabular}{lcccc}
\hline & & & $5^{\text {th }}$ & $95^{\text {th }}$ \\
& Mean & Median & Percentile & Percentile \\
\hline CDS1 & 131.46 & 36.74 & 7.80 & 543.38 \\
$C D S 3$ & 137.38 & 46.47 & 12.28 & 537.07 \\
$C D S 5$ & 141.78 & 56.72 & 17.09 & 518.50 \\
Leverage & 0.47 & 0.42 & 0.12 & 0.98 \\
Market Cap & $15,387.95$ & $5,249.85$ & 204.69 & $62,998.75$ \\
BTM & 21.10 & 0.86 & 0.21 & 42.16 \\
\hline
\end{tabular}

Panel B: Firms with options coverage

\begin{tabular}{lcccc}
\hline & & & $5^{\text {th }}$ & $95^{\text {th }}$ \\
& Mean & Median & Percentile & Percentile \\
\hline CDS 1 & 132.13 & 42.00 & 8.05 & 514.89 \\
$C D S 3$ & 137.98 & 51.77 & 12.17 & 510.25 \\
CDS5 & 143.38 & 61.50 & 16.63 & 500.00 \\
Leverage & 0.41 & 0.36 & 0.10 & 0.91 \\
Market Cap & $20,663.05$ & $7,866.84$ & 967.48 & $79,699.57$ \\
BTM & 5.25 & 0.73 & 0.18 & 11.95 \\
\hline
\end{tabular}

Panel C: Ratings Distributions

\begin{tabular}{lcc}
\hline & $\begin{array}{c}\text { All } \\
\text { firms }\end{array}$ & $\begin{array}{c}\text { Firms with } \\
\text { options data }\end{array}$ \\
\hline Number of firms with A rating & 1,790 & 841 \\
Number of firms with B rating & 5,893 & 2883 \\
Number of firms with C rating & 290 & 88 \\
Number of firms with no rating & 12,466 & 5203 \\
Total number of observations & 20,439 & 9015 \\
\hline
\end{tabular}


Table 4

Number of defaults per year

Defaults are identified each year from four sources (Moody's Default Risk Service, COMPUSTAT footnotes, Altman's bankruptcy list, BankruptcyData.com) in such a way that matches the default criteria specified in $C D S$ contracts' ISDA Master Agreement. Defaults in Moody's Default Risk Service database are included for the following categories: Bankruptcy, Bankruptcy Section 77, Chapter 10, Chapter 11, Prepackaged Chapter 11, distressed exchange, dividend omission, grace-period default, indenture modified, missed interest payment, missed principal and interest payments, missed principal payment, payment moratorium, suspension of payments. In COMPUSTAT database, defaults are included when footnote AFTNT35 is 2 (bankruptcy under Chapter 11) or 3 (bankruptcy under Chapter 7). Every default in Altman's bankruptcy list and BankruptcyData.com is included if it can be matched with a firm in the COMPUSTAT database. Matching is based on company names and other details provided and is confirmed by other sources, including Hoover and Factiva. For year 2005, the data cover up to the end of June.

\begin{tabular}{cccc}
\hline Year & $\begin{array}{c}\text { Defaults by } \\
\text { all firms }\end{array}$ & $\begin{array}{c}\text { Defaults by firms } \\
\text { with option data }\end{array}$ & $\begin{array}{c}\text { Number of } \\
\text { optionable stocks }\end{array}$ \\
\hline 1996 & 33 & 4 & 1,571 \\
1997 & 48 & 5 & 1,960 \\
1998 & 109 & 6 & 2,173 \\
1999 & 149 & 16 & 2,239 \\
2000 & 190 & 18 & 2,258 \\
2001 & 232 & 45 & 1,957 \\
2002 & 190 & 36 & 1,681 \\
2003 & 127 & 11 & 1,552 \\
2004 & 69 & 6 & 1,834 \\
2005 & 53 & 9 & 1,781 \\
\hline
\end{tabular}

those in a standard $C D S$ contract. For example, the distressed exchange or indenture modified categories correspond to the restructuring clause in a $C D S$ contract. The remaining categories of defaults in Moody's database typically correspond to the old bankruptcy codes.

Break-downs of defaults into each year are provided in Table 4. The third column of the table shows the number of defaults by firms with options coverage within the last 12 months prior to the default dates. The last column shows the total number of optionable stocks. As expected, optionable stocks only cover a fraction of the total number of bankruptcies. However, the number of defaults with option coverage displays a similar time-series pattern to the number of defaults identified from the total universe of stocks.

Moody's Default Risk Service provides ratings history of debt issues maintained in their database. Ratings for debts with different seniorities are not directly comparable. For this reason, Moody's also provides ratings estimates for senior rated classes of debts. If a firm has a senior rated debt, the estimate will be the same as the actual rating. Otherwise, a rating is estimated using a notching system. Moody's gives detailed explanations of this process on their website. I use these estimated ratings in this study to ensure they are comparable across firms. The distribution of ratings across firms in the sample is reported in Panel $\mathrm{C}$ of 
Table 3 .

\section{Estimated risk-neutral default probabilities}

Taking the $C D S$ premiums as efficient market prices, to have good estimates of risk-neutral loss rates, we need reliable estimates of risk neutral default probabilities. With this in mind, my objective in this section is to examine alternative specifications of the equity process and evaluate their ability to produce risk-neutral probabilities that fit the best with the data. The most general equity dynamics under examination is:

$$
\frac{d S_{t}}{S_{t}}=\left(r+h\left(S_{t}\right)\right) d t+\sigma S_{t}^{-\beta} d B_{t}^{\mathbb{Q} s}
$$

where $h\left(S_{T}\right)=b+c \sigma^{2} S^{-2 \beta}$. I will examine four variants of this setup. In all of these four setups, $\beta$ and $\sigma$ will always be estimated. In addition,

- Model I: both $b$ and $c$ are estimated

- Model II: $b$ is set to 0 and $c$ is estimated

- Model III: $c$ is set to 0 and $b$ is estimated

- Model IV: both $b$ and $c$ are set to 0 .

After initial data trimming, there are in total 4816 different secids over the 10-year period. For each firm, each month, if the number of option observations is more than 30 , a set of parameters will be estimated from the data, by minimizing the sum of squared pricing errors between market option prices and the model's prices. In order to ensure the reliability of estimates, numerical optimization routines are run repeatedly (maximum 20 runs) until there can be no further reduction in the sum of squared pricing errors. At a first glance, models II, III and IV are more restrictive than model I. Therefore, model I is guaranteed to yield the lowest pricing errors on all occasions. However, there is a chance of over-fitting with a more general setup, in which case estimation of redundant parameters only adds noise.

In addition, there has been so far no study systematically assessing the fitness of different hazard specifications. Model I is developed by Carr and Linetsky (2006) whereas model III is derived by Campi, Polbennikov, and Sbuelz (2005) and model IV corresponds to the simple $C E V$ process. Therefore, it is interesting to see which of these different models can provide the best fit to the data.

I will assess these four models using a variety of tests. But first of all, Table 5 presents summary statistics of the implied parameters of the four setups. It is interesting to see that the distribution of estimated $\beta$ and $\sigma$ look nearly identical for the first 3 models. For model IV however, estimated $\beta$ 's seem to be uniformly higher. This is understandable since under the first three setups, default can occur through 2 channels: (1) the "surprise" element which is controlled by $b$ and $c$; and (2) the "diffusive" element which is controlled by $\beta$ and $\sigma$. Because the first channel is completely shut down for setup IV, the burden of fitting the default probabilities falls entirely on the "diffusive" channel. 


\section{Table 5}

\section{Summary Statistics of Estimated Parameters}

Option data are obtained from Option Metrics from Jan 1996 - June 2005. The following options are excluded: (1) options with maturities less than 30 days or more than 1 year; (2) options with zero open interest; (3) options on stocks that pay dividends within their maturities; (4) options on stocks with prices less than $\$ 5$; (5) options too far away from the money $(|\ln (S / K)|>30 \%)$ - where S and K are, respectively, the underlying stock price and the strike price of the options. (6) options with a bid-ask spread greater than 50 percent of the option's price. Equity prices are assumed to follow the process:

$$
\frac{d S_{t}}{S_{t}}=\left(r+b+c \sigma^{2} S_{t}^{-2 \beta}\right) d t+\sigma S^{-\beta} d B_{t}^{\mathbb{Q} s}
$$

The parameters of the equity process, $b, c, \sigma$ and $\beta$, are estimated by minimizing the differences between the model-implied option prices and market prices, using the least square criterion on a monthly basis. $b$, $c, \sigma$ are constrained to be non-negative. $\beta$ is constrained between the unit interval. In minimizing the least square differences, numerical optimizations are run repeatedly (at most 20 runs) until no further improvement in the least square difference can be achieved. The following are eliminated: (1) optimizations with less than 30 option prices per month; (2) optimizations which require more than 20 runs; (3) optimizations that result in corner solutions. Four models are estimated. In model I, all four parameters are estimated. In model II, the constant coefficient of the jump intensity, $b$, is set to zero. In model III, $c$ is set to zero. In this model, jump intensity is a constant. In model IV, only $\sigma$ and $\beta$ are estimated. This model only allows default to happen through the diffusive forces due to the $C E V$ structure.

\begin{tabular}{lcccc}
\hline & mean & median & $\begin{array}{c}5^{\text {th }} \\
\text { percentile }\end{array}$ & $\begin{array}{c}95^{\text {th }} \\
\text { percentile }\end{array}$ \\
\hline Model I & & & & \\
\hline$b$ & 0.008 & 0.000 & 0.000 & 0.049 \\
$c$ & 0.097 & 0.000 & 0.000 & 0.459 \\
$\sigma$ & 1.614 & 0.916 & 0.330 & 5.000 \\
$\beta$ & 0.273 & 0.175 & 0.000 & 0.806 \\
number of estimates & 150329 & & & \\
\hline & & & & \\
Model II & & & & \\
\hline$c$ & 0.142 & 0.033 & 0.000 & 0.573 \\
$\sigma$ & 1.599 & 0.914 & 0.330 & 5.000 \\
$\beta$ & 0.270 & 0.172 & 0.000 & 0.800 \\
number of estimates & 150276 & & & \\
\hline & & & & \\
Model III & & & & \\
\hline$b$ & 0.021 & 0.006 & 0.000 & 0.084 \\
$\sigma$ & 1.637 & 0.921 & 0.329 & 5.000 \\
$\beta$ & 0.275 & 0.175 & 0.000 & 0.807 \\
number of estimates & 150400 & & & \\
\hline & & & & \\
Model IV & & & & \\
\hline$\sigma$ & 1.937 & 1.139 & 0.336 & 5.000 \\
$\beta$ & 0.314 & 0.223 & 0.000 & 0.843 \\
number of estimates & 149338 & & & \\
\hline
\end{tabular}




\subsection{Estimated parameters for firms leading up to defaults}

As a first test to see whether the estimated models indeed contain credit information about the underlying firms, I examine the pattern of average risk-neutral default probabilities for a sample of firms that eventually end up in default. As firms get closer to default, it is reasonable to expect the probabilities of default by these firms to show an increasing pattern.

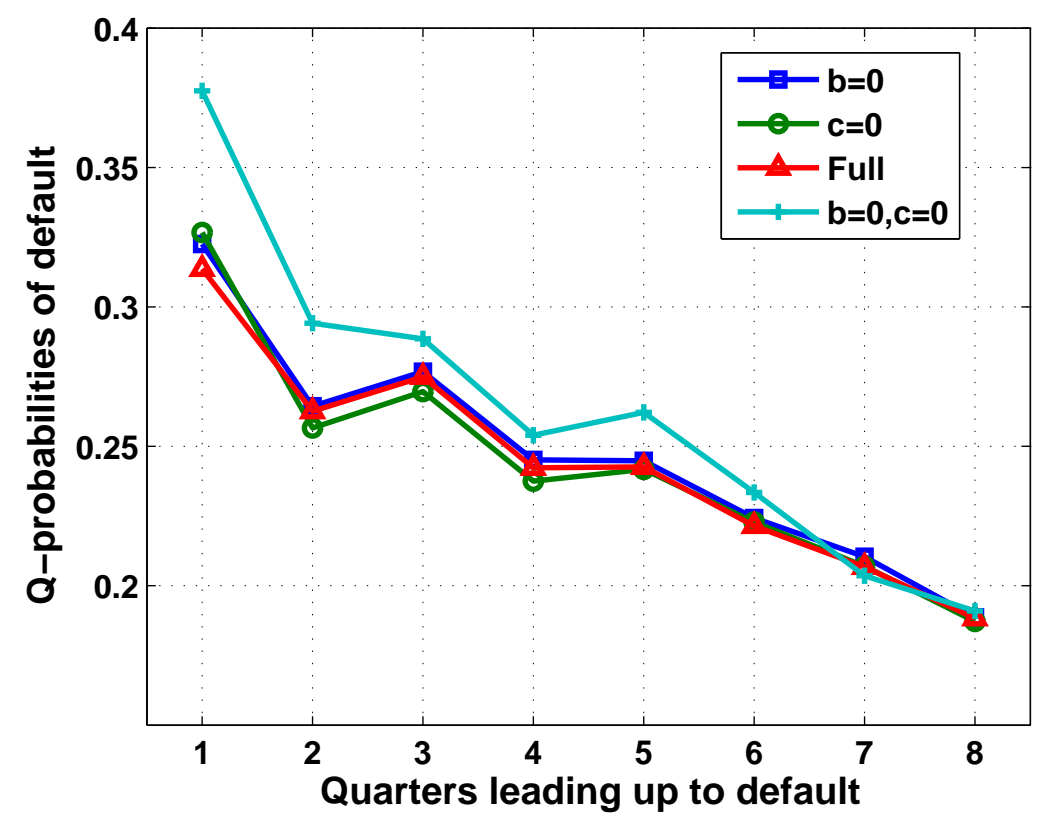

Figure 2 Risk Neutral Default Probabilities of Firms Leading up to Default

This figure plots average risk-neutral default probabilities (within five years) for a sample of firms that eventually default in the sample period from 1996 to 2005. Default probabilities are computed assuming equity prices follow:

$$
\frac{d S_{t}}{S_{t}}=\left(r+b+c \sigma^{2} S_{t}^{-2 \beta}\right) d t+\sigma S^{-\beta} d B_{t}^{\mathbb{Q} s}
$$

The parameters of the equity process, $b, c, \sigma$ and $\beta$, are estimated by matching model-implied to actual option prices using the least square criterion. Four variants of the models are estimated. Model I: full estimation. Model II sets $b=0$. Model III sets $c=0$. Model IV sets both $b$ and $c$ to zero.

As can be seen from Figure 2, the increasing pattern indeed can be observed from average probabilities generated by all four models. Starting from as low as $20 \%$ at 2 years prior to the actual defaults, the average default probabilities increase to nearly $40 \%$ as the firms get closer to the actual default date. It is interesting to see that the diffusive-only model - model IV - consistently assigns higher default probabilities than its diffusive-and-jump counterparts. In addition, models I, II and III's estimated default probabilities so closely resemble each other that their graphs almost become one. At least for the group of firms that eventually default, the diffusive-only model seems capable of producing better estimates of default probabilities. In results not reported here, I also rank default probabilities for every 


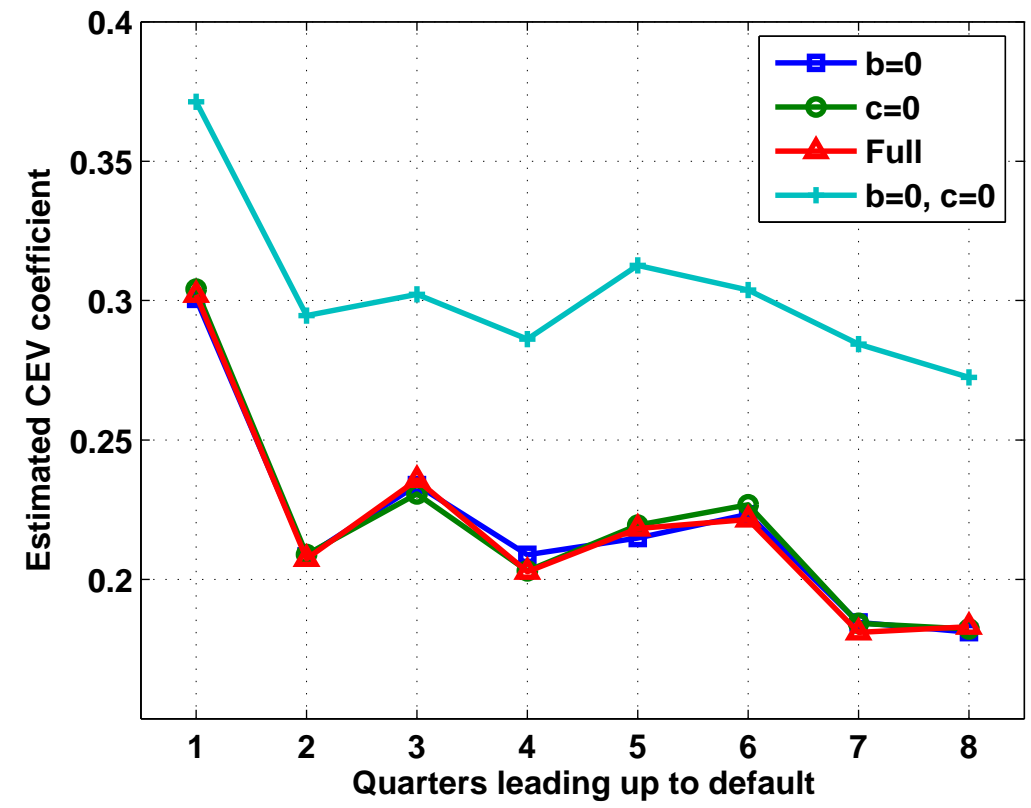

Figure 3 Estimated $C E V$ Coefficient of Firms Leading up to Default

This figure plots average $C E V$ estimates for a sample of firms that eventually default in the sample period from 1996 to 2005. Equity prices follow:

$$
\frac{d S_{t}}{S_{t}}=\left(r+b+c \sigma^{2} S_{t}^{-2 \beta}\right) d t+\sigma S^{-\beta} d B_{t}^{\mathbb{Q} s}
$$

The parameters of the equity process, $b, c, \sigma$ and $\beta$, are estimated by matching model-implied to actual option prices using the least square criterion. Four variants of the models are estimated. Model I: full estimation. Model II sets $b=0$. Model III sets $c=0$. Model IV sets both $b$ and $c$ to zero.

firm, each month, on a scale of 1-100 and plot the average ranks for the same sample of defaulted firms; a similar increasing pattern also emerges for all models.

The literature on $C E V$ models of equity prices (e.g. Christie (1982)) has attributed non-zero $C E V$ coefficient $\beta$ to the leverage effect. As long as the coefficient $\beta$ is positive, a leverage effect is always present within a $C E V$ model - a reduction in stock price will always lead to an increase in the conditional volatility of equity returns. The strength of the leverage effect is positively related to $\beta$. When $\beta=0$, there is no leverage effect. When $\beta=1$, the leverage effect is the strongest. For a sample of firms that are leading up to bankruptcies, it is reasonable to expect that the leverage effect is stronger as firms get closer to defaults. This suggests that there should be an increasing pattern in the average estimates of the $C E V$ coefficients for a sample of firms that eventually default. To examine whether this pattern is observed in my estimates, in Figure 3, I plot the average estimates of $\beta$ for the same sample of defaulted firms for the last 8 quarters before they eventually default. A pattern similar to the above plot of default probabilities, though to a lesser extent, can also be observed. The trend is most pronounced for the last quarter before default. Before that, the average estimates of $\beta$ are the same as the average $\beta$ taken over all firms. 


\subsection{Estimated risk-neutral default probabilities across ratings}

As a second test, I plot average risk-neutral default probabilities against different categories of credit ratings. Strictly speaking, credit ratings are not pure measures of default probabilities. In fact, they lump together default probabilities and recovery risks. ${ }^{34}$. However, it is certainly reasonable to expect that $\mathrm{Aaa}^{35}$ rated firms would have much lower probabilities of default than lower-rated firms.

As can be seen from Figure 4, all four models seem to differentiate default probabilities reasonably well across ratings. There is an obvious increasing pattern in default probabilities across the ratings spectrum from Aaa to C. The diffusion-and-jump models, except for the rating class Baa1 and above, exhibit sharp increasing patterns and once again lie on top of one another. It is interesting to see that these models assign much higher default probabilities to firms with investment grade ratings. For Aaa-rated firms, the actual default probability within 5 years is 1 out of 1000. As implied by the jump-to-default models, under the pricing measure, this probability is 1 out of 10 . This is not surprising since under the risk-neutral measure, the mean drift for every asset is the risk-free rate, therefore default occurs more often under this measure.

However, marked differences exist between default probabilities implied by the diffusiononly model and those implied by the other three models that allow for jumps. It is impossible to make judgment at this juncture which estimates are more reasonable by looking at this graph alone. However, prior studies (see, for example, Zhou (2001)) suggest that the diffusion-only model will not explain well short-term dynamics of credit risks. To this extent, evidence presented in the following section will confirm that in terms of magnitude, default probabilities generated by the diffusion-only model will, in most cases, significantly underestimate $C D S$ prices. It is not the case for the jump-and-diffusion models.

\subsection{Time series of estimated risk-neutral default probabilities}

Figure 5 plots the average risk-neutral probabilities of default for each year that option data and equity data are available (from 1996 to 2005). Each year, the default probabilities are averaged over firms with the same broad rating category: A, B or C as estimated by Moody's. Together with these average probabilities, the total number of defaults and the number of defaults by firms with options coverage (during the last 12 months before default) are also plotted. The period from 1996 to 2005 presents a credit cycle with a peak in 2002 which sees a record number of bankruptcies. It is interesting to see that default probabilities implied by all four models map reasonably well into this wave of bankruptcies with an apparent lag of one year.

In addition, Figure 5 confirms that the rankings of default probabilities across ratings, observed in the last subsection, are consistent over time. The monotonicity among default probabilities of different rating classes is observed in every year in the sample and for all

\footnotetext{
${ }^{34}$ Fitchs' Ratings have introduced two separate measures for under investment grade bonds only recently.

${ }^{35}$ Aaa is the highest rating category used by Moodys. The equivalent class of rating by Standard and Poor and Fitch's Ratings is AAA.
} 


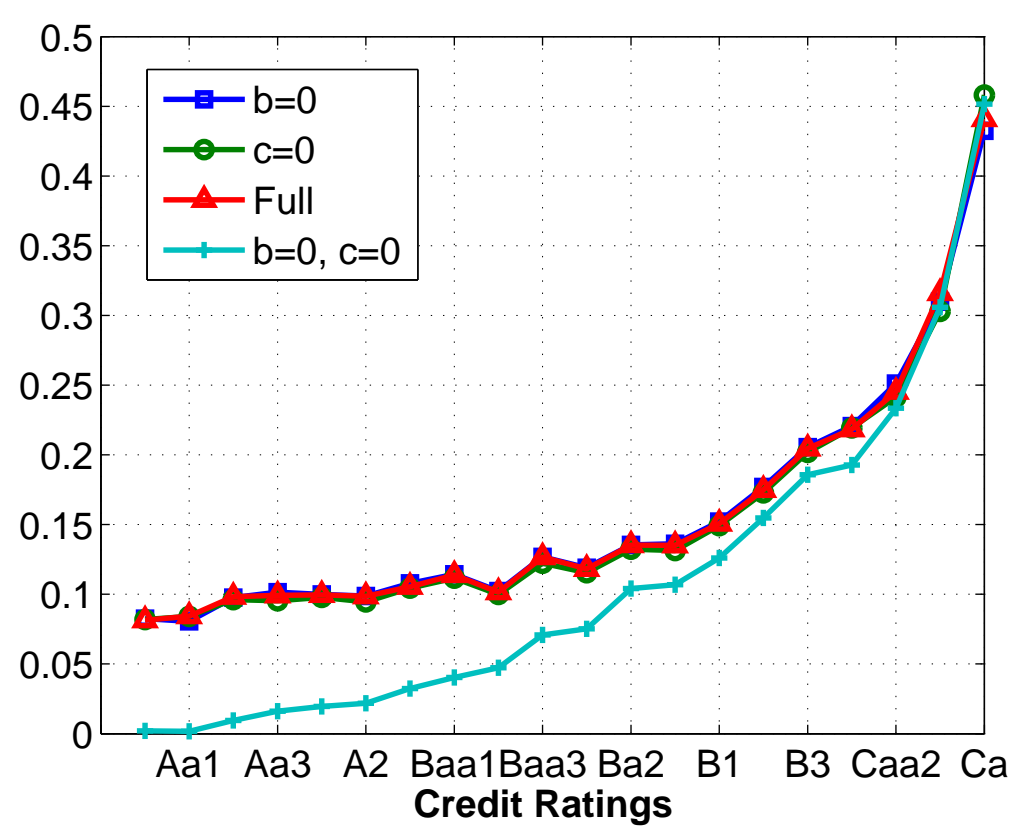

Figure 4 Estimated Risk Neutral Probabilities across Credit Ratings

This figure plots average risk-neutral default probabilities (within five years) for firms with the same senior credit ratings as estimated by Moody's. Default probabilities are computed assuming equity prices follow: $\frac{d S_{t}}{S_{t}}=\left(r+b+c \sigma^{2} S_{t}^{-2 \beta}\right) d t+\sigma S^{-\beta} d B_{t}^{\mathbb{Q} s}$

The parameters of the equity process, $b, c, \sigma$ and $\beta$, are estimated by matching model-implied to actual option prices, using the least square criterion. Four variants of the models are estimated. Model I: full estimation. Model II sets $b=0$. Model III sets $c=0$. Model IV sets both $b$ and $c$ to zero.

four models. The only exception is for firms with "C" ratings during the year of 1997. This is mainly due to the small number of C-rated firms used in computation of the averages. Moreover, in comparison to the diffusion-only model, models with jumps consistently assign considerably higher default probabilities for highly-rated firms. As discussed previously, this feature is important in matching the levels of the actual $C D S$ premiums.

From the above exercises, risk-neutral default probabilities estimated by all four models seem reasonable. In the next section, these default probabilities will be combined with data on $C D S$ premiums to learn about the dynamics of $L^{\mathbb{Q}}$. As discussed in subsection 3.4, a general structure of $L^{\mathbb{Q}}$ can, in principal, be estimated. Nevertheless, to preserve simplicity, I will assume that $L^{\mathbb{Q}}$ enters into the $C D S$ pricing formula as a constant. Consequently, $L^{\mathbb{Q}}$ can be computed as the ratio of actual $C D S$ premiums to predicted $C D S$ premiums, according to equation (36). The advantage of this simple approach is three-fold. First, having a constant $L^{\mathbb{Q}}$ enables efficiency in pricing $C D S$ contracts and implying $L^{\mathbb{Q}}$. Second, introducing additional parameters governing the dynamics of $L^{\mathbb{Q}}$ leads to a more flexible structure but it can also bring more statistical noise to the parameter estimates. Third, having a constant $L^{\mathbb{Q}}$ does not mean that we cannot study about the dynamics of $L^{\mathbb{Q}}$. $L^{\mathbb{Q}}$ 


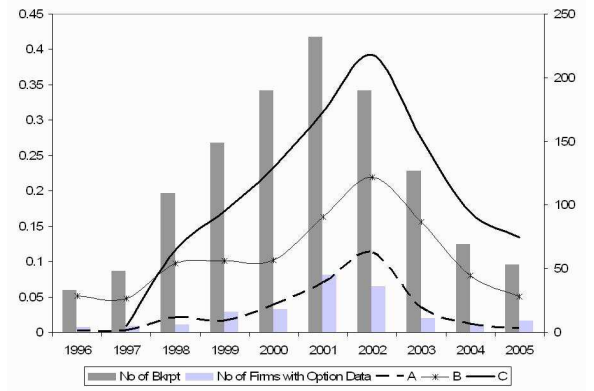

(a) Model IV: $b=0, c=0$

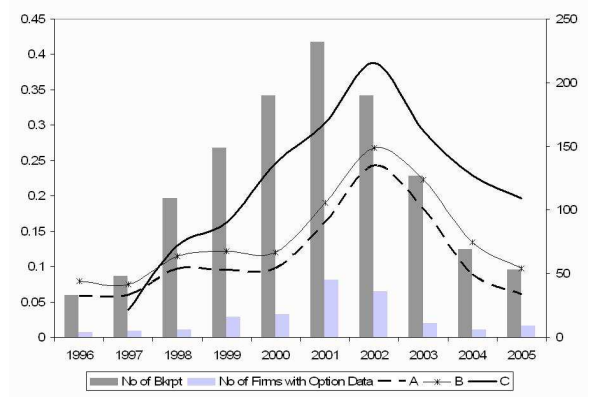

(c) Model III: $c=0$

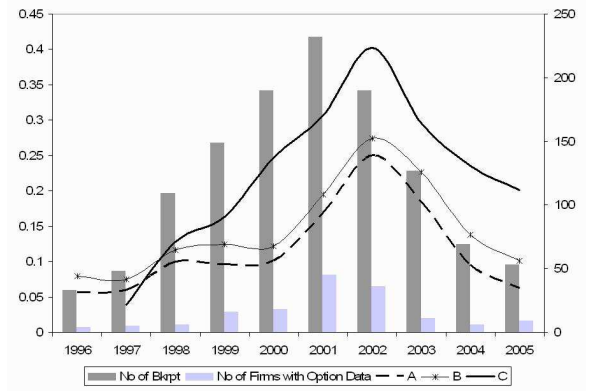

(b) Model II: $b=0$

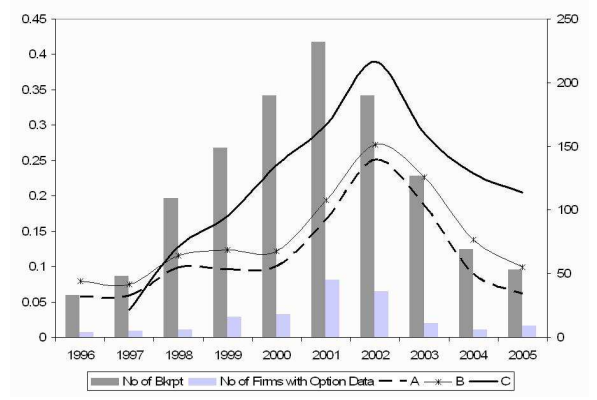

(d) Model I: full estimation

\section{Figure 5 Time Series of Estimated Risk-Neutral Default Probabilities}

This figure plots the average risk-neutral probabilities of default for each year that option data and equity data are available from 1996 to 2005. Each year, the default probabilities are averaged over firms with the same broad rating category: A, B or C as estimated by Moody's. These ratings correspond to the senior classes of debts. Together with these average probabilities, the total number of defaults and the number of defaults by firms with options coverage (during the last 12 months before default) are also plotted. Defaults are identified each year from four sources (Moody's Default Risk Service, COMPUSTAT footnotes, Altman's bankruptcy list, BankruptcyData.com) in such a way that matches the default criteria specified in $C D S$ contracts' ISDA Master Agreement. Default probabilities are computed assuming equity prices follow the process:

$$
\frac{d S_{t}}{S_{t}}=\left(r+b+c \sigma^{2} S_{t}^{-2 \beta}\right) d t+\sigma S^{-\beta} d B_{t}^{\mathbb{Q} s}
$$

The parameters of the equity process, $b, c, \sigma$ and $\beta$, are estimated by matching model-implied to actual option prices, using the least square criterion. Four variants of the models are estimated. Model I: full estimation. Model II sets $b=0$. Model III sets $c=0$. Model IV sets both $b$ and $c$ to zero.

implied from this framework still contains information about the loss rate the same way as Black-Scholes implied volatility is informative about the future standard deviation of equity returns. ${ }^{36}$

\footnotetext{
${ }^{36} \mathrm{With}$ regard to the central hypothesis of interest - the positive correlation between default probability and loss rate, setting $L^{\mathbb{Q}}$ to a constant amounts to assuming that $L^{\mathbb{Q}}$ and $\lambda^{\mathbb{Q}}$ are not related. In testing a positive relationship between $L^{\mathbb{Q}}$ and $\lambda^{\mathbb{Q}}$, this could be understood as a form of null hypothesis and any positive correlation between $L^{\mathbb{Q}}$ and $\lambda^{\mathbb{Q}}$ can be taken as evidence of deviation of the data from the null and in support of the alternative hypothesis.
} 


\section{$6 \quad$ Implied $L^{\mathbb{Q}}$}

To reduce the effect of market noise inherent in $C D S$ prices I compute monthly average $C D S$ premiums in stead of using daily data directly from ValuSpread. This averaging process also guards against possible staleness in prices where the same quotes for a particular reference name are mechanically provided to ValuSpread over consecutive days. In addition, it seems prevalent in the earlier periods of the sample that quotes on different firms are collected on different dates of the month. Therefore, cross-sectional analysis on two consecutive days may involve completely different sets of reference names. Averaging $C D S$ premiums over months substantially reduces this problem.

Combining these monthly averages of $C D S$ premiums with the default parameters implied from the equity and option markets, risk-neutral loss given default $L^{\mathbb{Q}}$ can be computed. Table 6 shows the number of valid $L^{\mathbb{Q}}$ estimates produced by each model of default for each of the three maturities pertaining to the $C D S$ contract, 1 year, 3 years and 5 years. An estimate of $L^{\mathbb{Q}}$ is valid if it falls within the unit interval. As expected, the diffusion-only model provides a very small number of valid estimates, particularly for short maturities. Over my sample period from 2002 to 2005, with one year to maturity, this type of model can only produce $734 C D S$ premiums whose levels are economically sensible (greater than 5 basis points) and out of these, only 138 lead to a valid estimate of $L^{\mathbb{Q}}$. Even for a horizon of five years - the most common maturity underlying $C D S$ contracts - pure diffusion models still have troubles matching the level of observed $C D S$ spreads. In contrast, all the other three models which allow for jump-to-defaults are able to match the levels of $C D S$ premiums quite well. The number of valid $L^{\mathbb{Q}}$ estimates produced by these models is five to ten times larger than that of their pure-diffusion counter-part. In the remaining part of the paper, I will only consider model II whose jump intensity is linearly related to the instantaneous volatility of returns. This model yields the highest number of valid estimates. As a check, all the exercises presented below are repeated for the other two jump models and no material differences in results can be found.

Figure 6 plots the average implied loss rate $L^{\mathbb{Q}}$ and the associated risk-neutral default probabilities $\lambda^{\mathbb{Q}}$ across different rating classes. The graphs are constructed using prices of $C D S$ contracts with five years to maturity but the same pattern is found with other maturities as well. In a risk-neutral sense, highly rated firms are characterized by low $\lambda^{\mathbb{Q}}$ as well as low $L^{\mathbb{Q}}$. At the other end of the spectrum, creditors of firms that are close to defaults are expected to recover much less in actual defaults.

To investigate whether the correlation between $L^{\mathbb{Q}}$ and $\lambda^{\mathbb{Q}}$ stems from any particular sub-period in the sample, I break the sample into quarters and compute the cross-sectional correlation between $L^{\mathbb{Q}}$ and $\lambda^{\mathbb{Q}}$ for each quarter. These correlations and other time series statistics of $L^{\mathbb{Q}}$ and $\lambda^{\mathbb{Q}}$ are reported in Table 7 . As can be seen, except for the third quarter of 2002, the correlation between $L^{\mathbb{Q}}$ and $\lambda^{\mathbb{Q}}$ is positive in every quarter in the sample. However, in the $4^{\text {th }}$ quarter of 2002 and the first two quarters of 2005, the correlation seems small in magnitude. One point worth mentioning at this juncture is that my procedure of 


\section{Table 6 \\ Number of valid $L^{\mathbb{Q}}$ estimates}

Option data are obtained from Option Metrics from Jan 1996 - June 2005. Exclusion criteria are described in the text of the paper. Equity prices are assumed to follow the process:

$$
\frac{d S_{t}}{S_{t}}=\left(r+b+c \sigma^{2} S_{t}^{-2 \beta}\right) d t+\sigma S^{-\beta} d B_{t}^{\mathbb{Q} s}
$$

The parameters of the equity process, $b, c, \sigma$ and $\beta$, are estimated by minimizing the differences between the model-implied option prices and market prices, using the least square criterion on a monthly basis. $b, c, \sigma$ are constrained to be non-negative. $\beta$ is constrained between the unit interval. Four models are estimated. In model I, all four parameters are estimated. In model II, the constant coefficient of the jump intensity, $b$, is set to zero. In model III, $c$ is set to zero. In this model, jump intensity is a constant. In model IV, only $\sigma$ and $\beta$ are estimated. This model only allows default to happen through the diffusive forces due to the $C E V$ structure. For each of these models, the estimated parameters $b, c, \sigma$ and $\beta$ are used to compute risk-neutral default probabilities. These probabilities are combined with $C D S$ premiums to form estimates of loss given default $L^{\mathbb{Q}}$. $C D S$ premiums are obtained from Fitch Rating's ValuSpread. Exclusion criteria are described in the text. $C D S$ premiums with 1,3 and 5 year(s) to maturity are used in estimating $L^{\mathbb{Q}}$. The "total" column reports the number of $L^{\mathbb{Q}}$ estimates in cases $b, c, \sigma$ and $\beta$ imply economically sensible $C D S$ spreads - greater than 5 basis points. The "valid" column reports the number of valid $L^{\mathbb{Q}}$ estimates. A valid estimate of $L^{\mathbb{Q}}$ must fall between 0 and 1 .

\begin{tabular}{|c|c|c|c|c|c|c|}
\hline \multirow[b]{2}{*}{ Model } & $\begin{array}{r}C \\
1 \text { yeal }\end{array}$ & $\begin{array}{l}\text { with } \\
\text { maturity }\end{array}$ & $\begin{array}{r}C \\
3 \text { yea }\end{array}$ & $\begin{array}{l}\text { with } \\
\text { maturity }\end{array}$ & $\begin{array}{r}\text { ( } \\
5 \text { yea }\end{array}$ & $\begin{array}{l}\text { with } \\
\text { maturity }\end{array}$ \\
\hline & valid & total & valid & total & valid & total \\
\hline I & 4134 & 4795 & 4890 & 5600 & 5084 & 5813 \\
\hline II & 4176 & 4796 & 4917 & 5602 & 5108 & 5825 \\
\hline III & 3946 & 4643 & 4728 & 5455 & 4919 & 5663 \\
\hline IV & 138 & 734 & 782 & 1615 & 1097 & 1800 \\
\hline
\end{tabular}

estimating $L^{\mathbb{Q}}$ is roughly equal to dividing the $C D S$ premiums by $\lambda^{\mathbb{Q} 37}$. If the estimates are contaminated with large errors, this procedure may artificially introduce a negative correlation between $L^{\mathbb{Q}}$ and $\lambda^{\mathbb{Q}}$. The fact that despite this possibility, a consistently positive relationship between $L^{\mathbb{Q}}$ and $\lambda^{\mathbb{Q}}$ can be found seems to reinforce their positive correlation.

Table 7 also reports cross-sectional averages of $L^{\mathbb{Q}}, \lambda^{\mathbb{Q}}$ and $C D S$ premiums with five years to maturity for every quarter in the sample. The sample averages of $L^{\mathbb{Q}}$ are around the range of values that have been adopted by prior researchers as well as practitioners (between $40 \%$ to $60 \%$ ). Apart from the very similar decreasing patterns of average $C D S$ premiums and average $\lambda^{\mathbb{Q}}$, it is striking to see that average $L^{\mathbb{Q}}$ seems to increase after the bankruptcy wave of the 2002. The sample period from 2002 to 2005 has observed a significant decrease in the number of bankruptcies and therefore $\lambda^{\mathbb{P}}$. In light of the widely documented positive correlation between $L^{\mathbb{P}}$ and $\lambda^{\mathbb{P}}$, it seems reasonable to conjecture that the current sample period is also coupled with a decrease in $L^{\mathbb{P}}$. Since the difference between $L^{\mathbb{P}}$ and $L^{\mathbb{Q}}$ is related to recovery risk premiums, a decreasing $L^{\mathbb{P}}$ and stability in $L^{\mathbb{Q}}$ suggest the overall recovery risk premium has decreased.

\footnotetext{
${ }^{37}$ This would be the case if the $C E V$ process collapses to a log-normal diffusion. In such a case, jump intensity is a constant $\lambda^{\mathbb{Q}}$ and $C D S$ premium is simply $\lambda^{\mathbb{Q}} L^{\mathbb{Q}}$.
} 


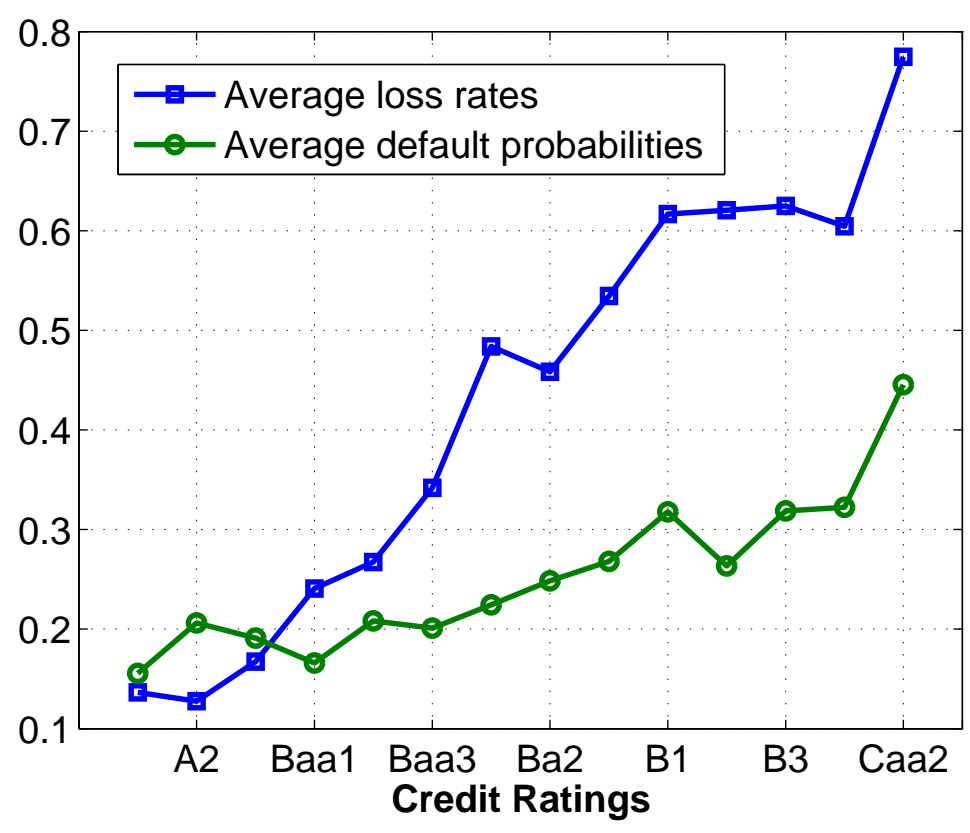

Figure 6 Loss Given Default and Default Probabilities by Ratings

Loss given defaults implied using $C D S$ premiums with five years to maturity and an equity model with Constant Elasticity of Variance and a jump to default component - the intensity of which is proportional to the conditional volatility of returns. Rating groups beyond A1 and Caa2 are not included because there are too few estimates within these ratings groups.

Given the positive correlation between $L^{\mathbb{Q}}$ and $\lambda^{\mathbb{Q}}$, an interesting question arises: what characteristics of the firm are driving this correlation? To investigate this issue, I regress $L^{\mathbb{Q}}$ and $\lambda^{\mathbb{Q}}$ on firm characteristics that could potentially affect both of these variables. The specification of these regressions is as follows:

$\lambda_{i}^{\mathbb{Q}}=a_{0}+a_{1}$ Leverage $_{i}+a_{2}$ Profitability $_{i}+a_{3}$ Tangibility $_{i}+a_{4}$ Qratio $_{i}+a_{5}$ Volatility $_{i}+\epsilon_{i}^{a}(38)$

$L_{i}^{\mathbb{Q}}=b_{0}+b_{1}$ Leverage $_{i}+b_{2}$ Profitability $_{i}+b_{3}$ Tangibility $_{i}+b_{4}$ Qratio $_{i}+b_{5}$ Volatility $_{i}+\epsilon_{i}^{b}(39)$

Leverage is measured as book value of long term debt divided by book value of asset. Profitability is the ratio of EBITDA to sales while tangibility is measured as the expenses on plant property and equipment divided by book value of assets. Volatility is historical volatility of daily returns on equity using a 90-day window. Since I use yearly balance sheet data from COMPUSTAT to measure firm characteristics, $L_{t}^{Q}$ and $\lambda^{\mathbb{Q}}$ are first averaged over each calendar year. I run the same regressions for each year in the sample and for the whole sample, controlling for fixed year effects. Results are reported in Table 8.

Of the five firm characteristics, leverage and volatility seem to be the most important and consistent factors in explaining the positive correlation between $L^{Q}$ and $\lambda^{\mathbb{Q}}$. The coefficients of leverage and volatility are statistically and economically significant for both $L^{Q}$ and $\lambda^{\mathbb{Q}}$. It shows that, on average, $1 \%$ increase in leverage leads to approximately $0.60 \%$ increase in $L^{Q}$ 


\section{Table 7}

\section{Time series statistics of $L^{\mathbb{Q}}$}

This table reports quarterly time series statistics of the implied loss given default measure $L^{\mathbb{Q}}$ using a $C E V$ model of equity with jumps where the jump intensity is proportional to the conditional return variance:

$$
\frac{d S_{t}}{S_{t}}=\left(r+c \sigma^{2} S_{t}^{-2 \beta}\right) d t+\sigma S^{-\beta} d B_{t}^{\mathbb{Q} s}
$$

The parameters of the equity process, $c, \sigma$ and $\beta$, are estimated by minimizing the differences between the model-implied option prices and market prices, using the least square criterion on a monthly basis. $c, \sigma$ are constrained to be non-negative. $\beta$ is constrained between the unit interval. The estimated parameters $c, \sigma$ and $\beta$ are used to compute risk-neutral default probabilities. $\lambda^{Q}$ denotes risk-neutral default probabilities with a five-year horizon. These probabilities are combined with $C D S$ premiums to form estimates of loss given default $L^{\mathbb{Q}}$. $C D S$ premiums and option prices are obtained, respectively, from Fitch Rating's ValuSpread and Option Metrics. Exclusion criteria are described in the text. $C D S$ premiums with 5 years to maturity are used in estimating $L^{\mathbb{Q}}$. The second column contains the cross-sectional correlation between $L^{\mathbb{Q}}$ and $\lambda^{\mathbb{Q}}$ for each quarter in the sample. The subsequent two columns report cross-sectional variances and sample means of $L^{\mathbb{Q}}$ for each quarter of the sample. The last two columns contain cross-sectional means of $C D S$ premiums, with five years to maturity, and $\lambda^{\mathbb{Q}}$.

\begin{tabular}{cccccc}
\hline Quarter & $\begin{array}{c}\text { correlation } \\
L^{\mathbb{Q}} \text { and } \lambda^{Q}\end{array}$ & $\begin{array}{c}\text { variance } \\
\text { of } L^{\mathbb{Q}}\end{array}$ & $\begin{array}{c}\text { mean } \\
\text { of } L^{\mathbb{Q}}\end{array}$ & $\begin{array}{c}\text { mean } \\
\text { of } C D S\end{array}$ & $\begin{array}{c}\text { mean } \\
\text { of } \lambda^{Q}\end{array}$ \\
\hline & & & & & \\
$2002-3$ & -0.15 & 0.06 & 0.45 & 0.0572 & 0.3913 \\
$2002-4$ & 0.00 & 0.06 & 0.41 & 0.0513 & 0.3839 \\
$2003-1$ & 0.12 & 0.05 & 0.42 & 0.0419 & 0.3368 \\
$2003-2$ & 0.18 & 0.06 & 0.52 & 0.0395 & 0.2536 \\
$2003-3$ & 0.28 & 0.07 & 0.50 & 0.0324 & 0.2288 \\
$2003-4$ & 0.18 & 0.07 & 0.57 & 0.0262 & 0.1720 \\
$2004-1$ & 0.07 & 0.06 & 0.55 & 0.0214 & 0.1579 \\
$2004-2$ & 0.21 & 0.07 & 0.59 & 0.0234 & 0.1454 \\
$2004-3$ & 0.05 & 0.06 & 0.49 & 0.0219 & 0.1930 \\
$2004-4$ & 0.22 & 0.06 & 0.55 & 0.0168 & 0.1281 \\
$2005-1$ & 0.02 & 0.07 & 0.53 & 0.0124 & 0.0970 \\
$2005-2$ & 0.02 & 0.09 & 0.55 & 0.0100 & 0.1207 \\
\hline
\end{tabular}

and $.14 \%$ in $\lambda^{\mathbb{Q}}$, holding everything else constant. Given the wide variations of leverage in the cross-section of firms, such a relationship between $L^{Q}$ and leverage implies significant crosssectional variations in $L^{\mathbb{Q}}$. Holding everything else constant, a firm with a $20 \%$ leverage will have a $L^{Q} 12 \%$ lower than that of an otherwise the same firm with a $40 \%$ leverage. Why should leverage be related to default probabilities and loss given default? Higher leverage leads to higher probabilities of default since higher leverage means larger fixed interest commitments a firm has to make every period. At the same time, as argued by Acharya, Bharath, and Srinivasan (2004), bankruptcy proceedings of high-leverage firms may be more difficult to resolve ${ }^{38}$. As such, higher leverage can lead to both higher $L_{t}^{\mathbb{Q}}$ and $\lambda^{\mathbb{Q}}$. Likewise, higher volatility means the chance a firm cannot fulfill its interest commitment during a period is higher, which means a higher $\lambda^{\mathbb{Q}}$. In addition, greater volatility of assets

\footnotetext{
${ }^{38}$ Because higher leverage may be associated with greater dispersed ownership requiring greater coordination among bargaining parties.
} 


\section{Table 8}

\section{Cross-sectional Analysis of $L^{\mathbb{Q}}$ and $\lambda^{\mathbb{Q}}$}

The following two cross-sectional regressions of yearly average risk-neutral default probabilities $\left(\lambda^{\mathbb{Q}}\right)$ and yearly average risk-neutral loss given default $\left(L^{\mathbb{Q}}\right)$ on firm characteristics are run in each year of the sample (2002, 2003, 2004, 2005) and the whole sample, controlling for fixed-year effects.

$$
\begin{aligned}
\lambda_{i}^{\mathbb{Q}} & =a_{0}+a_{1} \text { Leverage }_{i}+a_{2} \text { Profitability }_{i}+a_{3} \text { Tangibility }_{i}+a_{4} \text { Qratio }_{i}+a_{5} \text { Volatility }_{i}+\epsilon_{i}^{a} \\
L_{i}^{\mathbb{Q}} & =b_{0}+b_{1} \text { Leverage }_{i}+b_{2} \text { Profitability }_{i}+b_{3} \text { Tangibility }_{i}+b_{4} \text { Qratio }_{i}+b_{5} \text { Volatility }_{i}+\epsilon_{i}^{b}
\end{aligned}
$$

$L_{i}^{\mathbb{Q}}$ and $\lambda_{i}^{\mathbb{Q}}$ are estimated using a $C E V$ model of equity with jumps whose intensity is proportional to the conditional return variance:

$$
\frac{d S_{t}}{S_{t}}=\left(r+c \sigma^{2} S_{t}^{-2 \beta}\right) d t+\sigma S^{-\beta} d B_{t}^{\mathbb{Q} s}
$$

The parameters of the equity process, $c, \sigma$ and $\beta$, are estimated by minimizing the differences between the model-implied option prices and market prices, using the least square criterion on a monthly basis. $c, \sigma$ are constrained to be non-negative. $\beta$ is constrained between the unit interval. The estimated parameters $c, \sigma$ and $\beta$ are used to compute risk-neutral default probabilities $\lambda^{Q}$ for each month. These probabilities are combined with $C D S$ premiums, with five-year maturities, to form estimates of $L^{\mathbb{Q}}$. Monthly $L^{\mathbb{Q}}$ and $\lambda^{Q}$ are then averaged over each year. $C D S$ premiums and option prices are obtained, respectively, from Fitch Rating's ValuSpread and Option Metrics. Exclusion criteria are described in the text. Leverage, Profitability, Tangibility, and Qratio are, respectively, measured as debt/asset, EBITDA/sales, PPE/asset, firms' market value divided by asset. PPE stands for property, plant and equipment expense. Asset and debt (long-term debt + short-term debt), sales, PPE and EBITDA are book values and obtained, when available, from the COMPUSTAT quarter and annual files. Firms' market value is computed as (asset book value of equity + market cap). Price and shares outstanding data (in computing value of the firms) are obtained from the CRSP file. Volatility is standard deviation of equity returns, using a 90-day estimation

\begin{tabular}{|c|c|c|c|c|c|c|c|c|c|c|}
\hline & \multicolumn{2}{|c|}{ all years } & \multicolumn{2}{|c|}{2002} & \multicolumn{2}{|c|}{2003} & \multicolumn{2}{|c|}{2004} & \multicolumn{2}{|c|}{2005} \\
\hline & $\lambda^{\mathbb{Q}}$ & $L^{\mathbb{Q}}$ & $\lambda^{\mathbb{Q}}$ & $L^{\mathbb{Q}}$ & $\lambda^{\mathbb{Q}}$ & $L^{\mathbb{Q}}$ & $\lambda^{\mathbb{Q}}$ & $L^{\mathbb{Q}}$ & $\lambda^{\mathbb{Q}}$ & $L^{\mathbb{Q}}$ \\
\hline \multirow[t]{2}{*}{ Intercept } & 0.071 & 0.279 & 0.269 & 0.127 & 0.164 & 0.193 & 0.047 & 0.076 & 0.021 & 0.295 \\
\hline & 7.058 & 13.619 & 7.323 & 2.915 & 8.962 & 5.381 & 3.315 & 2.070 & 1.926 & 6.946 \\
\hline \multirow[t]{2}{*}{ Leverage } & 0.140 & 0.596 & 0.149 & 0.551 & 0.176 & 0.590 & 0.106 & 0.603 & 0.109 & 0.548 \\
\hline & 7.962 & 16.664 & 2.341 & 7.286 & 5.043 & 8.621 & 4.405 & 9.574 & 5.286 & 6.876 \\
\hline \multirow[t]{2}{*}{ Profitability } & -0.063 & -0.221 & -0.049 & -0.316 & -0.103 & -0.241 & -0.065 & -0.098 & -0.024 & -0.243 \\
\hline & -3.966 & -6.790 & -0.730 & -3.948 & -3.491 & -4.154 & -2.926 & -1.701 & -1.340 & -3.458 \\
\hline \multirow[t]{2}{*}{ Tangibility } & -0.054 & 0.025 & -0.170 & -0.013 & -0.066 & 0.019 & -0.024 & 0.046 & -0.017 & 0.037 \\
\hline & -5.199 & 1.186 & -4.347 & -0.279 & -3.267 & 0.471 & -1.743 & 1.260 & -1.275 & 0.728 \\
\hline \multirow[t]{2}{*}{ Qratio } & -0.014 & -0.039 & -0.033 & -0.037 & -0.013 & -0.040 & -0.011 & -0.036 & -0.006 & -0.041 \\
\hline & -5.114 & -6.868 & -3.104 & -2.912 & -2.447 & -3.998 & -2.840 & -3.542 & -1.678 & -3.143 \\
\hline \multirow[t]{2}{*}{ Volatility } & 0.226 & 0.200 & 0.349 & 0.195 & 0.148 & 0.125 & 0.341 & 0.625 & 0.292 & 0.200 \\
\hline & 19.066 & 8.331 & 8.094 & 3.796 & 9.487 & 4.062 & 12.843 & 9.016 & 14.879 & 2.648 \\
\hline$N$ & 1499 & 1499 & 267 & 267 & 401 & 401 & 469 & 469 & 347 & 347 \\
\hline $\operatorname{adj}-R^{2}$ & 0.561 & 0.3147 & 0.302 & 0.325 & 0.301 & 0.303 & 0.364 & 0.386 & 0.469 & 0.221 \\
\hline
\end{tabular}
horizon. For each variable, the first line contains point estimates while the second line contains t-statistics. $N$ and adj- $R^{2}$ are, respectively, the sample size and the adjusted- $R^{2}$ statistics of each regression. 


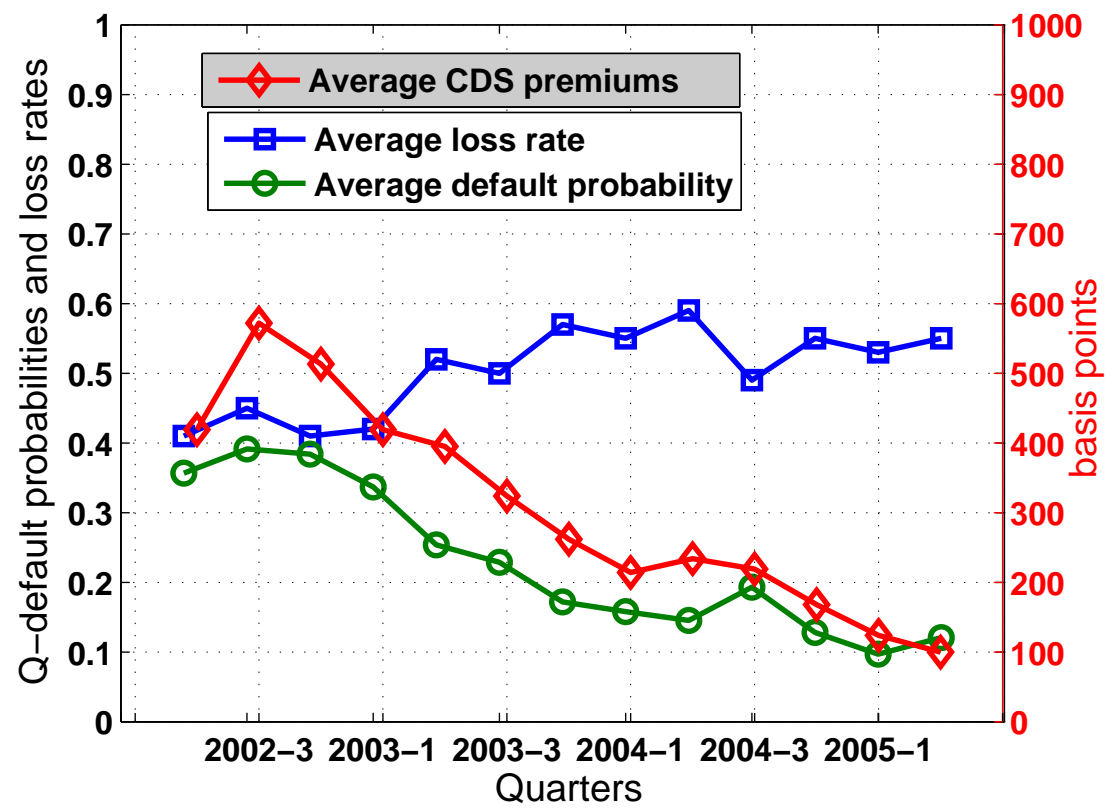

\section{Figure 7 Decomposing $C D S$ Premiums into Risk-neutral Expected Loss Given Default and Default Probabilities}

Cross-sectional averages of $L^{\mathbb{Q}}$ are computed for each quarter for the sample period 2002:2005. $L^{\mathbb{Q}}$ measures are implied using a $C E V$ model of equity with jumps where the jump intensity is proportional to the conditional returns variance and $C D S$ premiums with five years to maturity. The blue line (with squares) graphs quarterly $L^{\mathbb{Q}}$ averages while the green line (with circles) plots the quarterly average of default probabilities during the next five years. The red line (with diamonds) represents quarterly averages of $C D S$ premiums.

increases the chance that a firm defaults with a very low asset value, which in turn increases $L^{\mathbb{Q}}$.

To a lesser extent, firms' profitability and q-ratios are also responsible for the correlation between $L_{t}^{Q}$ and $\lambda_{t}^{\mathbb{Q}}$. As can be seen in Table 8, higher profitability causes both $L_{t}^{Q}$ and $\lambda^{\mathbb{Q}}$ to be lower. This is intuitive since more profitable firms are capable of producing more sustainable cash-flows and thus more capable of fulfilling their interest obligations. What is more, profitable firms are likely to own more productive assets which could fetch for more in case of defaults. Therefore higher profitability is associated with both lower $\lambda^{\mathbb{Q}}$ and lower $L_{t}^{\mathbb{Q}}$. In terms of q-ratios, higher q-ratio means higher future growth and possibly larger future cash-flows, thus lowering the chance of default. At the same time, firms with high potentials tend to find solutions to liquidity-driven defaults and return to productivity quicker (by refinancing or court protection), expected loss given default on these firms is lower. Hence a high q-ratio lowers both $\lambda^{\mathbb{Q}}$ and $L_{t}^{\mathbb{Q}}$.

With regard to the tangibility of firms' assets, $\lambda^{\mathbb{Q}}$ are negatively related to tangibility while no relationship between tangibility and $L^{\mathbb{Q}}$ can be found. In the pooled regressions 
and in the year of 2002 and 2003, the relationship between tangibility and $\lambda_{t}^{\mathbb{Q}}$ is statistically significant. However, these coefficients become insignificant in 2004 and 2005. This change in significance can be explained as follows. Tangibility could be viewed as the extent to which the assets of the firms can be used as security for extra debt, holding everything else constant, thus proxying for the extra debt capacity of the firm. The easier a firm can get refinancing when needed, the less likely a firm will default on its existing debts. This extra debt capacity is particularly important in tight credit environments as is the case in 2002. This explains why both coefficients estimates and t-statistics of the tangibility variable decrease over the sample period.

On the other hand, tangibility is insignificant in every regression of $L^{\mathbb{Q}}$. This result is somewhat puzzling since tangible assets are easier to transfer among firms and thus should reduce $L^{\mathbb{Q}}$ in case of defaults. This puzzle could be due to several reasons. First, the variable being used (Plant Property and Equipment Expense divided by Total Assets) may not be a good proxy for tangibility. To this extent, I have tried other variables used in the literature that proxy for the tangibility/specificity of firms' assets such as industry median equipment and machinery expense divided by total assets, industry median Q-ratio ${ }^{39}$, amortized $R \& D$ expense divided by total assets ${ }^{40}$, and the results remain the same. Second, the effect of tangibility may have been already captured by other variables. For example, firms may choose their level of leverage taking the degree of tangibility of their assets into account. To this extent, I re-run the above analysis using univariate regressions of $L^{\mathbb{Q}}$ on tangibility and other asset-specificity variables mentioned above but find no meaningful relationship. Third, it could be that asset specificity/tangibility does not affect $L^{\mathbb{Q}}$ but does affect recovery risk premium $\pi_{t}^{R}$. In fact, Acharya, Bharath, and Srinivasan (2004) find that in a distressed industry, physical loss rates are related to the asset-specificity of the firm. Interpreting the evidence here together with results from Acharya, Bharath, and Srinivasan (2004) in the context of equation (38), it suggests that in distressed industries, the degree of assetspecificity is directly related to the uncertainty of recovery in default thereby inducing a higher recovery risk premium. This is also the conclusion reached by Acharya, Bharath, and Srinivasan (2004) but their conclusion relies on the systematic nature of the industry variables.

Finally, the difficulty in measuring asset tangibility and specificity, as recognized in the literature, means that proxies for this characteristic may be estimated with large errors. These estimation errors may explain the insignificance results found with various tangibility and asset specificity measures. Moreover, at least part of the specificity/tangibility of the assets should already be reflected in stock prices and hence firms' market value and q-ratios. To this extent, the fact that firms' q-ratios are significantly negatively related to both $\lambda^{\mathbb{Q}}$ and $L^{\mathbb{Q}}$ suggests that asset tangibility/specificity may, at least partly, have been captured by q-ratios.

\footnotetext{
${ }^{39}$ Acharya, Bharath, and Srinivasan (2004)

${ }^{40}$ Gabudean (2006)
} 


\section{Concluding Remarks}

In summary, I have set out a general pricing framework that allows the risk-neutral dynamics of $L^{\mathbb{Q}}$ and $\lambda^{\mathbb{Q}}$ to be separately and sequentially discovered. This framework allows, in principle, for a general specification of $L^{\mathbb{Q}}$ and its dependency on $\lambda^{\mathbb{Q}}$ or other exogenous factors. In light of the recent Basel Capital Accord which emphasizes the importance of managing value at risk, this framework can serve as a platform to further enhance our understanding of the dynamics of loss given default.

Using equity and option data, I show that one can efficiently extract pure measures of $\lambda^{\mathbb{Q}}$ that are not contaminated by recovery information. Equipped with this knowledge of pure default dynamics, prices of any defaultable security on the same firm with non-zero recovery can be inverted to compute the associated $L^{\mathbb{Q}}$ corresponding to that particular security. Using $C D S$ data, I show that cross-sectionally $L^{\mathbb{Q}}$ and $\lambda^{\mathbb{Q}}$ are positively correlated. This evidence lends support to a recent finding that industry distressed condition rather than the supply and demand of defaulted securities is responsible for the positive correlation between default rates and losses observed in the data. Firm characteristics including leverage, volatility, profitability and q-ratios are found to explain the positive correlation between $L^{\mathbb{Q}}$ and $\lambda^{\mathbb{Q}}$.

The empirical applications of the current framework can be extended in many directions. The equity process can be specified in a way that incorporates debt data in a similar manner to a Merton-type structural model. The use of a translated Geometric Brownian Motion process used in JPMorgan's E2C model and Das and Sundaram (2003) is an example. This will combine the advantages of: (1) the economic structure of the Merton framework; (2) the extra information by using both debt and equity data; and (3) the jump-to-default dynamics present in the current setting. In addition, the current framework can also be implemented using credit spreads from the bond market. Given the flexibility of the current framework in accommodating different recovery assumptions, dynamics of recoveries implicit from the bond market itself can be studied and compared under the three different recovery assumptions. 


\section{Appendix}

\section{A Iterative computation of the probabilities matrix}

At each step $N$, let's denote $A_{N}$ to be an $(N+1) \times(N+1)$ matrix that contains all possible combinations of $S_{t+N \Delta t}$ and $r_{t+N \Delta t}$. The rows correspond to different values of $S$ while the columns represent $r$. So $A_{N}(i, j)$ refers to a pair of numbers $S_{N}(i)$ and $r_{N}(j)$. Let $P_{N}$ be an $(N+1) \times(N+1)$ matrix that gives probabilities of each element of $A_{N}$ conditional on the starting point $S_{t}$ and $r_{t}$, that is:

$$
P_{N}(i, j)=P\left(S_{t+N \Delta t}=S_{N}(i), r_{t+N \Delta t}=r_{N}(j) \mid S_{t}, r_{t}\right)
$$

To compute $P_{N+1}$ at step $N+1$, note that $S_{N+1}(i)$ can only be arrived from $S_{N}(i)$ or $S_{N}(i-1)$ and $r_{N+1}(j)$ can only be arrived from $r_{N}(j)$ or $r_{N}(j-1)$

$$
P_{N+1}(i, j)=\sum_{k_{i}=0,-1 ; k_{j}=0,-1} P\left(S_{N+1}(i), r_{N+1}(j) \mid S_{N}\left(i+k_{i}\right), r_{N}\left(j+k_{j}\right)\right) \times P_{N}\left(i+k_{i}, j+k_{j}\right)
$$

Since $S_{N}$ and $r_{N}$ are conditionally independent,

$P\left(S_{N+1}(i), r_{N+1}(j) \mid S_{N}\left(i+k_{i}\right), r_{N}\left(j+k_{j}\right)\right)=P\left(S_{N+1}(i) \mid S_{N}\left(i+k_{i}\right), r_{N}\left(j+k_{j}\right)\right) P\left(r_{N+1}(j) \mid r_{N}\left(j+k_{j}\right)\right)$

The particular functional forms of $P\left(S_{N+1}(i) \mid S_{N}\left(i+k_{i}\right), r_{N}\left(j+k_{j}\right)\right)$ and $P\left(r_{N+1}(j) \mid r_{N}\left(j+k_{j}\right)\right)$ are specified in the construction of the binomial trees for $S_{t}$ and $r_{t}$.

In matrix form,

$$
\begin{aligned}
P_{N+1}= & {\left[\begin{array}{lc}
0 & \mathbf{0} \\
\mathbf{0} & f_{d d}\left(A_{N}\right) \cdot * P_{N}
\end{array}\right] } \\
& +\left[\begin{array}{cc}
\mathbf{0} & f_{u d}\left(A_{N}\right) \cdot * P_{N} \\
0 & \mathbf{0}
\end{array}\right] \\
& +\left[\begin{array}{cc}
\mathbf{0} & 0 \\
f_{d u}\left(A_{N}\right) \cdot * P_{N} & \mathbf{0}
\end{array}\right] \\
& +\left[\begin{array}{cc}
f_{u u}\left(A_{N}\right) \cdot * P_{N} & \mathbf{0} \\
\mathbf{0} & 0
\end{array}\right]
\end{aligned}
$$

where $f_{u d}\left(A_{N}\right)$ gives the transition probabilities for each of the pair in matrix $A_{N}$ when $S$ goes up and $r$ goes down. $f_{u u}, f_{d u}, f_{d d}$ can be similarly defined. $\mathbf{0}$ (in bold form) denotes a vector of zero and $*$ denotes element by element matrix product. 


\section{References}

Acharya, V., Bharath, S., Srinivasan, A., 2004. Understanding the recovery rates of defaulted securities. Unpublished working paper. London Business School.

Acharya, V., Carpenter, J., 2002. Corporate bond valuation and hedging with stochastic interest rates and endogeneous bankruptcy. The Review of Financial Studies 15, 13551383.

Ahn, D., Gao, B., 1999. A parametric nonlinear model of term structure dynamics. Review of Financial Studies 12, 721-762.

Altman, E., 1968. Financial ratios, discriminant analysis and the prediction of corporate bankruptcy. Journal of Finance Sep, 589-609.

Altman, E., Brady, B., Resti, A., Sironi, A., 2005. The link between default and recovery rates: Theory, empirical evidence and implications. Journal of Business 78, 2203-2228.

Altman, E., Kishore, V., 1996. Almost everything you wanted to know about recoveries on defaulted bonds. Financial Analysts Journal Nov/Dec, 57-64.

Bakshi, G., Madan, D., Zhang, F., 2006. Recovery risk in defaultable debt models: Empirical comparisons and implied recovery rates. Unpublished working paper. University of Maryland.

Bharath, S., 2006. Do managers feather their own nests? evidence from absolute priority violations. Unpublished working paper. Michigan University.

Black, F., Cox, J., 1976. Valuing corporate securities: Liabilities: Some effects of bond indenture provisions. Journal of Finance 31, 351-367.

Campi, L., Polbennikov, S., Sbuelz, A., 2005. Assessing credit with equity: A cev model with jump to default. Unpublished working paper. Tilburg University.

Carr, P., Linetsky, V., 2006. A jump to default extended cev model: An application of bessel processes. Unpublished working paper. Courant Institute.

Carr, P., Wu, L., 2005. Stock options and credit default swaps: A joint framework for valuation and estimation. Unpublished working paper. Courant Institute.

Christie, A., 1982. The stochastic behavior of common stock variances: Value, leverage and interest rate effects. Journal of Financial Economics 10, 407-432.

Cox, J., Ingersoll, J., Ross, S., 1985. A theory of the term structure of interest rates. Econometrica 53(2), 385-407.

Cremers, M., Driessen, J., Maenhout, P., Weinbaum, D., 2004. Individual stock option prices and credit spreads. Unpublished working paper. Yale School of Management. 
Das, S., 2005. Recovery risk. Journal of Investment Management 3, 113-120.

Das, S., Hanouna, P., 2006. Implied recovery. Unpublished working paper. Santa-Clara University.

Das, S., Sundaram, R., 2003. Defaultable equity, option prices and credit-risk measurement: A separable approach. Unpublished working paper. New York University.

, 2006. A simple model for pricing securities with equity, interest-rate, and default risk. Unpublished working paper. New York University.

Duffie, D., Singleton, K., 1999. Modeling term structures of defaultable bonds. Review of Financial Studies 12, 687-720.

Eom, Y., Helwege, J., Huang, J.-Z., 2004. Structural models of corporate bond pricing: An empirical analysis. The Review of Financial Studies 17, 499-544.

Frank, J., Torous, W., 1989. An empirical investigation of us firms in reorganization. Journal of Finance 44, 747-769.

Frye, J., 2000. Depressing recoveries. Unpublished working paper. Federal Reserve Bank of Chicago.

Gabudean, R., 2006. Strategic interaction and the co-determination of firms financial policies. Unpublished working paper. New York University.

Geske, R., 1977. The valuation of corporate securities as compound options. Journal of Financial and Quantitative Analysis 12, 541-552.

Gilson, S., John, K., Lang, L., 1991. Troubled debt restructurings: An empirical study of private reorganization of firms in default. Journal of Financial Economics 27, 355-387.

Guo, X., Jarrow, R., Zeng, Y., 2005. Modeling the recovery rate in a reduced form model. Unpublished working paper. Cornel University.

Huang, J., Huang, M., 2003. How much of the corporate-treasury yield spread is due to credit risk? a new calibration approach. Unpublished working paper. Stanford University.

Hull, J., Nelken, I., White, A., 2004. Merton's model, credit risk, and volatility skews. Unpublished working paper. University of Toronto.

Hull, J., White, A., 1995. The impact of default risk on the prices of options and other derivative securities. Journal of Banking and Finance 19, 299-322.

Jarrow, R., 2001. Default parameter estimation using market prices. Financial Analysts Journal 57, 75-92. 
Jarrow, R., Lando, D., Turnbull, S., 1997. A markov model for the term structure of credit spreads. Review of Financial Studies 10, 481-523.

Jarrow, R., Turnbull, S., 1995. Pricing options on financial securities subject to default risk. Journal of Finance 50, 53-86.

Kim, J., Ramaswamy, K., Sundaresan, S., 1993. Does default risk in coupons affect the valuation of corporate bonds? a contingent claims model. Financial Management 22, $117-131$.

Lando, D., 1998. On cox processes and credit risky securities. Review of Derivatives Research $2,99-120$.

Linetsky, V., 2006. Pricing equity derivatives subject to bankruptcy. Mathematical Finance $16,255-282$.

Linnell, I., Merritt, R., 2004. Liquidity in the credit default swap market: Too little too late?. Unpublished working paper. FitchRatings.

Litterman, R., Iben, T., 1991. Corporate bond valuation and the term structure of credit spreads. Journal of Portfolio Management 17, 52-64.

Longstaff, F. A., Schwartz, E. S., 1995. A simple approach to valuing risky fixed- and floatingrate debt. Journal of Finance 50, 789-819.

Madan, D., Unal, H., 1998. Pricing the risks of default. Review of Derivatives Research 2, $121-160$.

Merton, R., 1974. On the pricing of corporate debt: The risk structure of interest rates. Journal of Finance 29, 449-470.

Nelson, D., Ramaswamy, K., 1990. Simple binomial processes as diffusion approximations in financial models. The Review of Financial Studies 3, 393-430.

Ofek, E., Richardson, M., Whitelaw, R., 2004. Limited arbitrage and short sales restrictions: Evidence from the options markets. Journal of Financial Economics 74, 305-342.

Pan, J., Singleton, K., 2006. Default and recovery implicit in the term structure of sovereign cds spreads. Unpublished working paper. MIT and Stanford Universities.

Samuelson, P., 1972. Mathematics of speculative price. in Mathematical Topics in Economic Theory and Computation. Society for Industrial and Applied Mathematics.

Unal, H., Madan, D., Guntay, L., 2001. Pricing the risk of recovery in default with apr violation. Unpublished working paper. University of Maryland.

Vasicek, O., 1977. An equilibrium characterization of the term structure. Journal of Financial Economics 5, 177-188. 
— , 1984. Credit valuation. KMV Corporation March.

Zhou, C., 2001. The term structure of credit spreads with jump risk. Journal of Banking and Finance 25, 2015-2040. 